\title{
Complex Oligosaccharide Utilization Pathways in Lactobacillus
}

\author{
Manuel Zúñiga*, María Jesús Yebra and Vicente \\ Monedero
}

Instituto de Agroquímica y Tecnología de Alimentos (IATA-CSIC); Avenida Agustín Escardino 7, 46980

Paterna, Valencia, Spain.

*manolo@iata.csic.es

DOI: https://doi.org/10.21775/cimb.040.049

\begin{abstract}
Lactobacillus is the bacterial genus that contains the highest number of characterized probiotics. Lactobacilli in general can utilize a great variety of carbohydrates. This characteristic is an essential trait for their survival in highly competitive environments such as the gastrointestinal tract of animals. In particular, the ability of some strains to utilize complex carbohydrates such as milk oligosaccharides as well as their precursor monosaccharides, confer upon lactobacilli a competitive advantage. For this reason, many of these carbohydrates are considered as prebiotics. Genome sequencing of many lactobacilli strains has revealed a great variety of genes involved in the metabolism of carbohydrates and some of them have already been characterized. In this review, the current knowledge at biochemical and genetic levels on the catabolic pathways of complex carbohydrates utilized by lactobacilli will be summarized.
\end{abstract}

\section{Introduction}

All animals establish symbiotic associations with microbes. Paramount among these is the establishment of complex microbial communities in the gastrointestinal tract. These communities may comprise thousands of species and are particular of each individual (Eckburg et al., 2005; Ley et al., 2006; Turnbaugh et al., 2009). The composition and distribution of microbiota changes along the gastrointestinal tract reflecting the differing physicochemical conditions and epithelial surfaces that the microbes find in the different compartments of the gastrointestinal tract (Gu et al., 2013; Kim and Isaacson, 2015; Stearns et al., 2011; Tropini et al., 2017). For example, Lactobacillaceae are predominantly found in the stomach and small intestine of mice whereas anaerobes such as Bacteroidaceae, Prevotellaceae, Rikenellaceae, Lachnospiraceae and Ruminococcaceae are mainly found in the large intestine and feces (Gu et al., 2013). In the oral cavity of humans, a neutral pH and aerobic conditions prevail although anaerobic niches are also present. The environment in the stomach is acidic and microaerophilic whereas $\mathrm{pH}$ increases and oxygen availability decreases along the small intestine and colon. Nutrient availability and immune effectors also vary along the gastrointestinal tract. Furthermore, microbes are not uniformly distributed along the transverse axis of the gut (Tropini et al., 2017). Species such as Akkermansia muciniphila and some Bacteroides sp. are thought to be predominantly associated with the mucus layer whereas closer to the mucosa, aerotolerant taxa such as Proteobacteria and Actinobacteria are more abundant due to the radial oxygen gradient established across the intestinal wall (Albenberg et al., 2014).

Numerous studies have demonstrated that gut microbiota has a great influence on manifold host physiology aspects, from metabolism ( $\mathrm{Li}$ et al., 2008) to behavior (Ezenwa et al., 2012). Perturbation of the gut microbiota may markedly affect the host health (Cho and Blaser, 2012; Claesson et al., 2012) and has been related to a number of diseases such as metabolic disorders (Sonnenburg and Backhed, 2016), inflammatory diseases (Blander et al., 2017), diabetes (Membrez et al., 2008; Vaarala et al., 2008), coeliac disease (Collado et al., 2007), etc. Although the microbiota associated to an individual may display some resilience to perturbation (Lozupone et al., 2012; Sommer et al., 2017), external environmental factors such as food intake (Kohl et al., 2014) and composition (David et al., 2014) can alter it 
substantially. This aspect is pivotal in the relationship between microbiota and host nutrition and health as the gastrointestinal microbiota provide important metabolic capabilities, including the ability to obtain energy from indigestible dietary polysaccharides (Goh and Klaenhammer, 2015). The human genome encodes only 17 glycosidases enabling the utilization of a very limited set of polysaccharides (Cantarel et al., 2012; Goh and Klaenhammer, 2015). Therefore, most complex carbohydrates are available to gut microbes able to utilize these compounds.

Carbohydrates, as oligo- and polysaccharides or as glycoconjugates constitute an amazingly diverse group of molecules due to the structural diversity and numerous bonding sites of their constituent monosaccharides that allow their assembly among themselves or to almost any other organic molecule in a wide array of architectures. Because of this structural versatility, carbohydrates fulfill a wide variety of functions in organisms as structural polymers, energy reserve, signaling, etc. Furthermore, as a major component of human diet, carbohydrates also have a determining influence on the interactions between host and associated microbiota (Hooper et al., 2002). In addition to dietary carbohydrates, host-derived glycans constitute a secondary source of carbohydrates for gut microbiota (Hooper et al., 2002).

Although the gut microbiota taken as a whole can utilize a wide variety of glycans, cells belonging to individual taxa can usually metabolize a limited set of them. From this fact stems the concept of prebiotic, defined as a nondigestible food ingredient that beneficially affects the host by selectively stimulating the growth and/or activity of one or a limited number of bacteria in the colon, and thus improves host health (Gibson and Roberfroid, 1995). Prebiotics were first thought of as a means to selectively enrich probiotic gut microbes, specifically Lactobacillus and Bifidobacterium (Gibson and Roberfroid, 1995; Goh and Klaenhammer, 2015). Although not limited by the definition, all prebiotics are glycans. The definition of prebiotic has been revised and the specific stimulatory effect of prebiotics on lactobacilli and bifidobacteria has been challenged (Hutkins et al., 2016). Notwithstanding, the original idea gave a strong boost to the study of the glycan catabolic pathways of these organisms.

Lactobacillus is a large genus currently comprising over 200 species that have been isolated from a wide variety of habitats. They are Gram-positive, microaerophilic or anaerobic obligate fermentative organisms that produce lactic acid as the major end product of sugar fermentation. Together with genera Paralactobacillus, Pediococcus and Sharpea they constitute the family Lactobacillaceae within the order Lactobacillales. Lactobacillus strains play a major role in the production of a wide variety of fermented products. Others are naturally associated to mucosal surfaces of humans and animals and have been considered as probiotics (Tannock, 2004). Either as foodstuff fermenters or as probiotics, their capacity to utilize glycans is an important trait for their performance. This review focuses on our current knowledge on the pathways of complex glycan dissimilation identified in species of Lactobacillus.

\section{Fructan and fructooligosaccharide catabolic pathways}

\section{Structural characteristics of fructans}

Fructans are linear or branched fructose polymers and can be broadly divided into inulins ( $\beta$-2,1-linked) and levans ( $\beta-2,6$-linked) (Fuchs, 1991) (Figure 1). Fructans are usually synthesized from sucrose by repeated fructosyl transfer so that they have a terminal glucose unit. Levans are produced by many microorganisms, including some lactobacilli (Bello et al., 2001; Tieking et al., 2003; Van Geel-Schutten et al., 1999), and a few plant species (Öner et al., 2016). In contrast, inulins are relatively common in plants, especially Asteraceae, but only a few bacterial species produce them, among them, some Lactobacillus and Leuconostoc species (Anwar et al., 2008; Olivares-Illana et al., 2003; van Hijum et al., 2002). While bacterial fructans have a very high degree of polymerization (DP) up to $10^{5}$ fructose units, the DP of plant-derived fructans does generally not exceed DP 100. High DP of bacterial fructans is possibly related to their function as structural components of biofilms, but they also constitute an extracellular nutrient reservoir (Öner et al., 2016). In plants, fructans serve essentially as reserve carbohydrates.

Synthesis of fructans is catalyzed in bacteria by fructosyltransferases, named inulosucrases (EC 2.4.1.9) when they synthesize inulin, and levansucrases (EC 2.4.1.10) when they produce levan. Levansucrases can also form $\beta$-2,1-fructosylfructose linkages either to synthesize inulin-type fructooligosaccharides (FOS) or to create branching points that connect the $\beta-2,6$-linked chains of the polymer (Öner et al., 2016). In contrast to bacteria, the biosynthesis of fructans in plants is catalysed by 
three different classes of enzymes: sucrose:sucrose 1-fructosyltransferase (EC 2.4.1.99) (1-SST), fructan:fructan 1-fructosyltransferase (EC2.4.1.100) (1-FFT) and fructan exohydrolase (EC.3.2.1.153) (1FEH) (van Arkel et al., 2013). 1-SST primarily catalyses the synthesis of the trisaccharide 1kestose, from two molecules of sucrose. In this reaction glucose is formed in equimolar amounts to 1 -kestose ( $\beta$-D-fructofuranosyl- $(2 \rightarrow 1)-\beta-D$ fructofuranosyl-( $2 \rightarrow 1)$ - $\alpha$-D-glucopyranoside). 1-FFT catalyses the transfer of fructosyl units from 1kestose and any other fructan molecule onto 1kestose and higher DP fructan molecules. 1-FEH, catalyses the degradation of inulin by hydrolysing terminal fructosyl units, which results in the formation of fructose and lower DP inulin (van Arkel et al., 2013).

\section{Metabolic pathways for fructans utilization}

The interest on fructans in relation to the intestinal microbiota stemmed from the search of carbohydrate sources that reached the large intestine and were selectively used by beneficial microbes such as bifidobacteria. Several studies noted that fructooligosaccharides derived from inulin hydrolysis (usually referred to as FOSs) were not hydrolyzed by the host endogenous enzymes but efficiently used by bifidobacteria (Hidaka et al., 1986; Yazawa and Tamura, 1982). FOS naturally occur in many kinds of plants but they are commercially produced from the hydrolysis of inulin or synthesized from sucrose by transfructosylation by $\beta$-fructofuranosidases or $\beta$-D-fructosyltransferases (Goh and Klaenhammer, 2015). The most utilized natural source of inulins is chicory and depending on the method of extraction the product obtained may be almost exclusively FOS of the $G_{n}$ type (a glucose monomer linked $\alpha-1,2$ to two or more $\beta$-2,1-linked fructosyl units) or a mixture of $\mathrm{GF}_{\mathrm{n}}$ and $\mathrm{F}_{\mathrm{m}}$ type (two or more $\beta$-2,1-linked fructosyl units) oligomers (Roberfroid et al., 1998).

However, the first studies that reported the utilization of fructans by lactobacilli were focused in
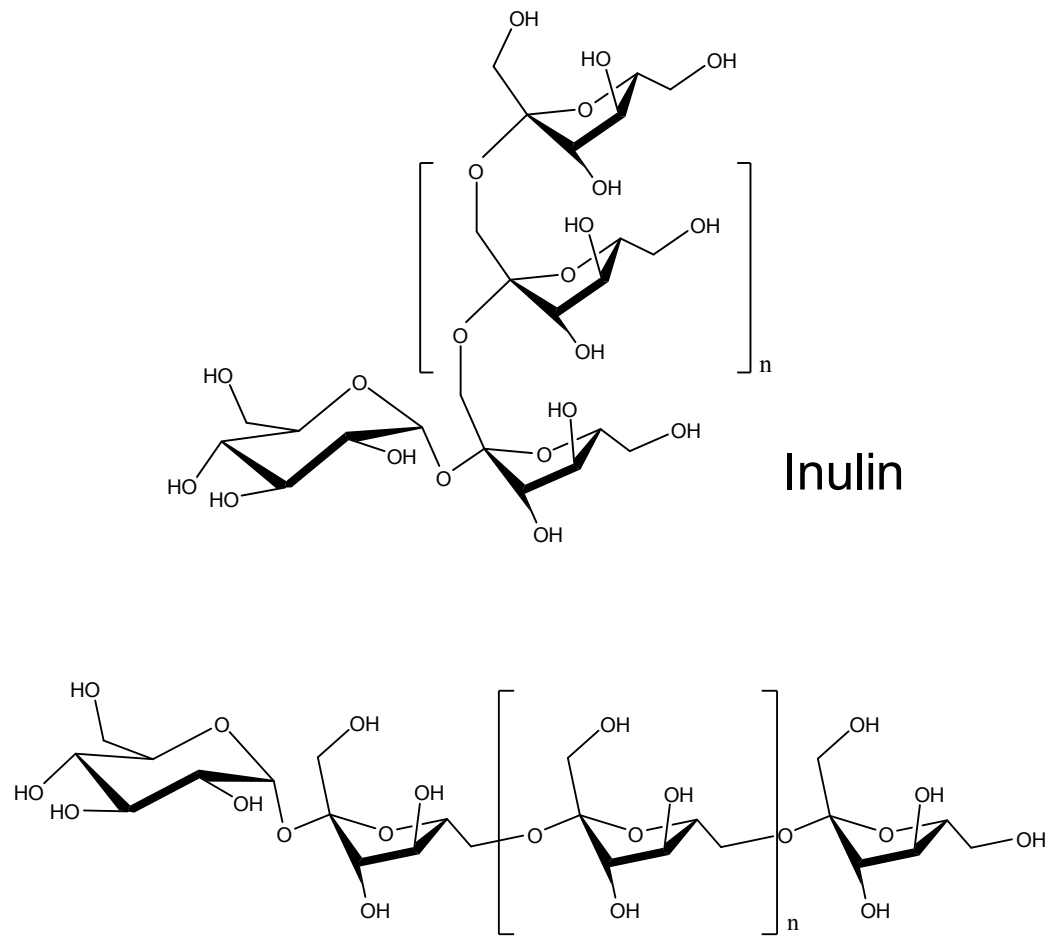

Levan

Figure 1. Chemical structures of inuline and levan. 
the usage of lactic acid bacteria for ensilage and showed that some lactobacilli could utilize fructans for growth (Kleeberger and Kühbauch, 1976). In a later study, it was shown that sixteen strains out of 712 were able to degrade levan and eight of them could also degrade inulin (Müller and Lier, 1994). Subsequent studies confirmed the ability of some lactobacilli to degrade fructans (Merry et al., 1995; Müller and Steller, 1995; Winters et al., 1998) although the enzymes and pathways involved were not determined. Other studies also established that some lactobacilli could grow on FOSs as carbon sources (Kaplan and Hutkins, 2000; Sghir et al., 1998). The characterization of an extracellular fructan hydrolase from Lactobacillus paracasei ssp. paracasei $\mathrm{P} 4134$ provided the first clues on the fructan degradative pathways of lactobacilli (Müller and Seyfarth, 1997). The enzyme hydrolized $\beta-2,6$ linked fructans more rapidly than $\beta-2,1$ linked fructans and the main product of hydrolysis was fructose, suggesting that the enzyme is an exofructanase (Müller and Seyfarth, 1997). Later studies on other $L$. casei/paracasei have confirmed these conclusions (Kuzuwa et al., 2012; Velikova et al., 2017). Subsequently, another extracellular fructanhydrolase purified from Lactobacillus pentosus B235 was characterized (Paludan-Müller et al., 2002). The purified enzyme had the highest activity for levan, but also hydrolysed garlic extract, a $\beta-2,1$-linked fructan with $\beta-2,6$ linked fructosyl sidechains, 1,1,1-kestose, 1,1-kestose, 1-kestose, inulin and sucrose at $60,45,39,12,9$ and $3 \%$, respectively, of the activity observed for levan (Paludan-Müller et al., 2002).

Genome sequencing and transcriptomic analyses paved the way for the identification and characterization of genes involved in the utilization of fructans. The studies carried out so far have characterized three different fructan utilization pathways in Lactobacillus acidophilus, Lactobacillus casei and Lactobacillus plantarum that differ in their transport systems and fructofuranosidase enzymes (Figure 2).

In 2003, Barrangou et al. (Barrangou et al., 2003) identified an operon $(\mathrm{msm})$ involved in FOS utilization by Lactobacillus acidophilus NCFM. The $\mathrm{msm}$ operon consisted of genes encoding for a transcriptional regulator of the Lacl family $(m s m R)$, an $A B C$ transport system (msmEFGK), a fructosidase (bfrA) and a sucrose phosphorylase (gtfA; Figure 3) (Barrangou et al., 2003). Similar operons can be detected in a limited number of strains of other species of lactobacilli (Figure 3 ). In Lactobacillus delbrueckii, Lactobacillus perolens, Lactobacillus saniviri and Lactobacillus concavus strains, a gene encoding a putative fructokinase is associated to the $\mathrm{msm}$ cluster (Figure 3 ). The transcriptional analysis of the $\mathrm{msm}$ operon of $L$.

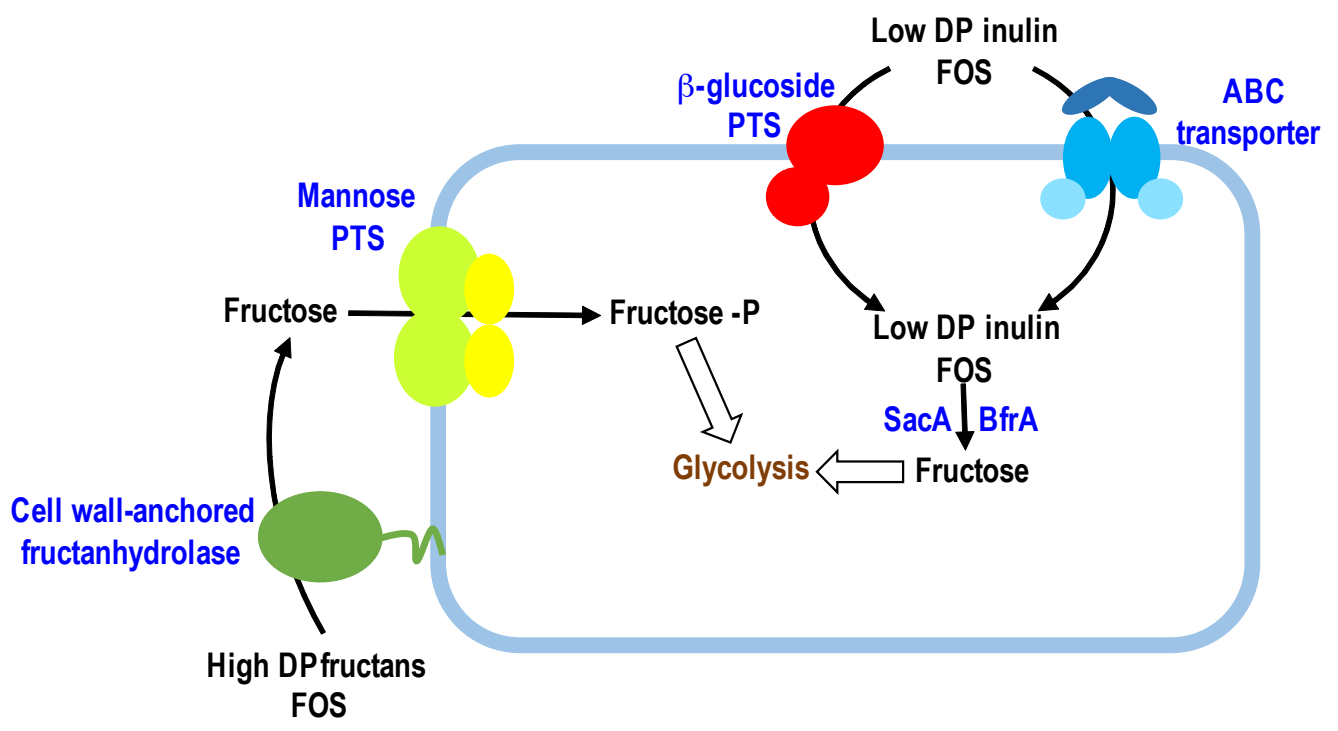

Figure 2. Fructan utilization pathways characterized in $L A B$. 
acidophilus NCFM showed that all genes were transcribed in a single transcriptional unit (Barrangou et al., 2003). Sucrose and oligofructose (both $\mathrm{GF}_{\mathrm{n}}$ and $\mathrm{F}_{\mathrm{n}}$ types) induced the expression of the operon whereas glucose and fructose did not. The expression of the operon was repressed by glucose suggesting that it is subjected to carbon catabolite repression (CCR). This hypothesis was further supported by the presence of several CRElike sites in the $\mathrm{msm}$ promoter region. The functionality of the operon was shown by inactivation $m s m E$ and $b f r A$ that resulted in defective growth on FOS- $F_{n}$ (Barrangou et al., 2003).

A comparative analysis of $L$. ruminis strains of human and bovine origin led to the identification of an operon possibly involved in FOS utilization consisting of a $\beta$-fructan hydrolase and an oligosaccharide $\mathrm{H}^{+}$sympoter ( $\mathrm{O}^{\prime}$ Donnell et al.,
2011) although experimental evidence is still lacking.

In Lactobacillus plantarum WCFS1, a gene cluster consisting of a putative fructokinase (sacK1), a putative phosphoenolpyruvate-dependent phosphotranferase transport system (PTS) of the $\beta$ glucoside family ( $p$ ts1BCA), a $\beta$-fructofuranosidase $(\operatorname{sac} A)$, a Lacl family transcriptional regulator $(\operatorname{sac} R)$ and a putative a-glucosidase (ag/2) (Figure 3), was induced when this strain was grown in the presence of low molecular weight FOS (Saulnier et al., 2007). The biochemical characterization of the $L$. plantarum ST-III SacA demonstrated that the enzyme has exofructofuranosidase activity with preference for $\beta-2,1$ linkages between two fructose moieties in fructans with low DP (Chen et al., 2014). The heterologous expression of SacA in Lactobacillus rhamnosus GG, an organism that can utilize fructose but not FOS, enabled this strain to
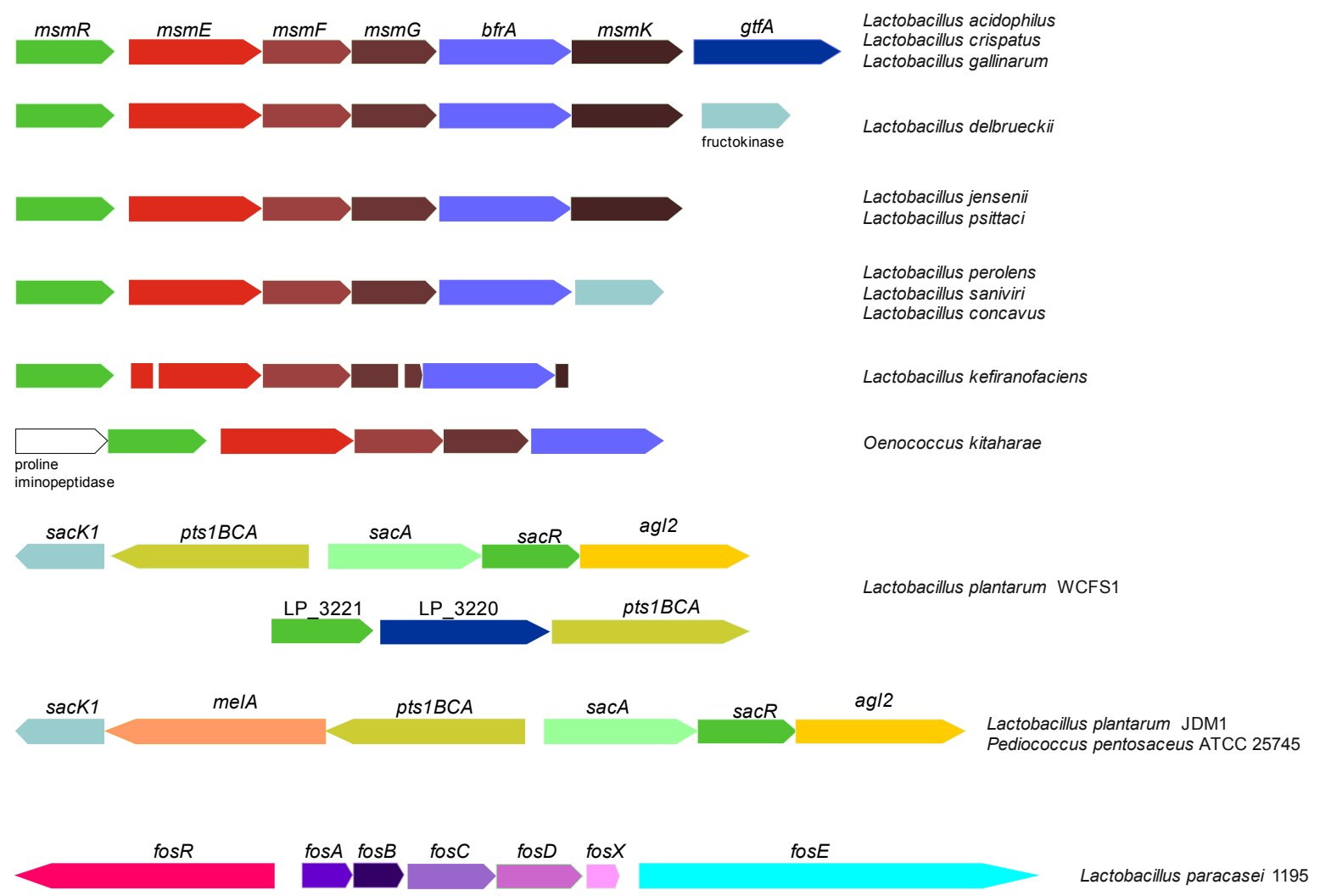

Figure 3. Schematic representation of fructan utilization gene clusters present in selected lactobacilli. Colors indicate homologous genes. Arrows indicate directionality. Interrupted arrows indicate translational frameshifts. 
grow on FOSs, thus demonstrating the functional role of this enzyme (Chen et al., 2014). Furthermore, inactivation of sacA in L. plantarum ST-III severely impaired the growth of this strain on FOSs (Chen et al., 2015). In contrast, a mutant defective in pts1BCA still could grow with FOSs although at a lower growth rate than the wild-type strain (Chen et al., 2015). A transcriptomic analysis of this strain had detected a second putative sac (sacPTS26) gene cluster constituted by a $\beta$ glucoside PTS (PTS26), an a-glucosidase (Agl4), and a transcriptional regulator (SacR2), that was also induced in the presence of FOSs (Chen et al., 2015). A double mutant pts1BCA/pts26 was unable to grow on FOS, indicating that both transporters are required for optimal FOS uptake and utilization (Chen et al., 2015). This second sac cluster is also present in L. plantarum WCFS1 (Figure 3) but it was not detected as upregulated in the presence of FOS in this strain (Saulnier et al., 2007) and its involvement in FOS utilization in WCFS1 remain to be determined (Chen et al., 2015). It is also intriguing the presence of $\alpha$-glucosidase encoding genes in sac clusters. The functional role of these genes remains to be established.

As mentioned above, L. paracasei utilizes an extracellular fructanhydrolase. Goh et al. (Goh et al., 2006) determined that the genes required for FOS utilization by $L$. paracasei 1195 are organized in a cluster (fosRABCDXE) encoding a putative mannose family PTS transporter (fos $A B C D X$ ), a $\beta$ fructosidase (fosE) and, divergently transcribed, a transcriptional antiterminator (fosR) (Figure 3). Homologous clusters are found in other $L$. caseil paracasei but considerable variability is observed. For example, L. paracasei ATCC 334 fosE homolog (LSEI_0564) lacks the C-terminal part including the cell-wall anchor motif whereas this gene is absent in strain BL23 (Figure 3). This variability may account for the conflicting observations of extracellular or cell-wall anchored fructanhydrolase activity in different $L$. paracasei strains. Inactivation of fosE led to the loss of the ability to grow on sucrose, FOS, oligofructose ( $F F_{n}$ type), inulin and levan, thus demonstrating the functionality of the operon (Goh et al., 2006). Furthermore, introduction of fosE into Lactobacillus rhamnosus GG enabled this strain to utilize FOS (Goh et al., 2007). The analysis of the FosE encoding sequence revealed an N-terminal signal peptide sequence and an LPQAG cell wall anchor motif at the C-terminal region, suggesting its localization at the cell wall. Cell fractionation assays confirmed this hypothesis as FOS hydrolysis activity was present exclusively in the cell wall extract of $L$. paracasei previously grown on FOS (Goh et al., 2007). In agreement with a previous biochemical characterization of a fructanhydrolase of $L$. paracasei (Müller and Seyfarth, 1997), the analysis of the degradation products of L. paracasei 1195 FosE indicated that it is an exofructanhydrolase (Goh et al., 2007). The transcriptional regulation of the fos cluster has also been studied. Expression of fos genes is induced in the presence of FOS, inulin, and to a lesser extent, sucrose and fructose but repressed by glucose (Goh et al., 2007; Goh et al., 2006). A CRE sequence is present in the lev promoter region, suggesting that the operon is subjected to CCR via the P-Ser-HPr/CcpA complex (Goh et al., 2006).

The role of FosR has not been addressed in $L$. paracasei 1195, however the functional role of the homologous LevR of strain BL23 has been studied (Mazé et al., 2004). The intergenic regions of fosRfosA and levR-levA in strain BL23 differ only in a single nucleotide and the FosABCD proteins shared more than $99 \%$ identity with their BL23 counterparts (Goh et al., 2006). LevR is homologous to the Bacillus subtilis LevR transcriptional regulator, which controls the expression of a mannose-class PTS transporter and a levanase involved in levan utilization. B. subtilis LevR interacts with the $\sigma^{54}$ factor and its activity is modulated via phosphorylation by by $\mathrm{P}$-His-HPr and P-EllBLev (Martin-Verstraete et al., 1998). In contrast, BL23 strain LevR do not require $\sigma^{54}$ although the regulation of its activity by phosphorylation still occurs by dual PTS-catalyzed phosphorylation at conserved histidine residues in the ElIA and PRD2 domains of LevR by P-His-HPr and P-His-EllBLev, respectively (Mazé et al., 2004). When the PTSLev transporter is active, P-His-EllB Lev preferably donates its phosphoryl group to the transported sugar, leading to dephosphorylation of LevR at His-776 by P-His-EllBLev and LevR activation and thereby induction of the lev PTS. On the other hand, when metabolically preferred PTS sugars, such as glucose, are present, the phosphoryl group of $\mathrm{P}$-His$\mathrm{HPr}$ is used for sugar phosphorylation. Poor phosphorylation at His-488 by $\mathrm{P}$-His-HPr renders LevR less active and downregulates expression of the lev PTS.

The different strategies of fructan utilization by lactobacilli possibly determine their abilities to utilize different fructans. Internalization and subsequent hydrolysis possibly limits the ability of fructan utilization to low DP oligosaccharides whereas extracellular degradation would enable the 
utilization of high DP fructans. Experimental evidence available supports this view. Makras et al. (Makras et al., 2005) assayed the capacity of ten strains of lactobacilli to degrade inulin-type fructans, observing that $L$. acidophilus only degraded oligofructose whereas L. paracasei could also degrade long-chain inulin. L. plantarum could utilize short-chain fructooligosaccharides but grew poorly with FOS (Saulnier et al., 2007). It has been proposed that the different strategies of fructan utilization in lactobacilli may respond to different ecological strategies. Internalization and subsequent degradation eliminates cross-feeding while conferring an advantage in a nutrientcompetitive environment. On the other hand, extracellular degradation let other organisms profit of the hydrolytic products thereby allowing the establishment of symbiotic relationships with other members of the community (Goh and Klaenhammer, 2015).

\section{Metabolism of glucans and glucooligosaccharides}

\section{Structural characteristics of glucans}

Lactobacillus species are equipped with the enzymatic machinery to utilize multiple glucan structures, which consist of glucose homopolymers with different linkages and branching types. However, the presence of these capacities is species- and strain-specific and usually linked to particular niche adaptations. Glucans can be classified into $\alpha$ - and $\beta$-glucans depending on the type of glycosidic bond present in the molecules (Figure 4). Starch is the main example of a-glucan and it represents the major carbon storage polysaccharide in plants. It is made of linear glucose chains with $\alpha-1,4$ linkages with high DP (amylose) and shorter chains which in addition to $\alpha-1,4$ bonds possess around $5 \%$ of $\alpha-1,6$ branching of 18 to 25 glucoses (amylopectine). Other $\alpha$-glucans can be linear or branched and carry diverse bonds ( $\alpha-1,2$; $\alpha-1,3)$ in addition to $\alpha-1,4$ and $\alpha-1,6$. Most of these glucans are produced by bacteria and fungi, such as dextrans ( $\alpha-1,6$ with $\alpha-1,3$ branching; Figure 4) produced by strains of lactobacilli such as Leuconostoc mesenteroides (Chen et al., 2016), Weisella cibaria (Malang et al., 2015) or Lactobacillus sakei (Nácher-Vázquez et al., 2017), reuteran ( $\alpha-1,4$ with $\alpha-1,6$ branching), synthesized by Lactobacillus reuteri (Chen et al., 2016) or pullulan (maltotriose units linked by $\alpha-1,6$ bonds; Figure 5), produced by Aureobasidium pullulans (Cheng et al., 2011). Isomaltooligosaccharides (IMO) are a type of $\alpha$-glucans that are gaining interest due to their prebiotic effects (Ketabi et al.,
2011; Leemhuis et al., 2014; Yen et al., 2011). They are short $\alpha-1,6$-linked glucans (e.g. isomaltose [a-Dglucopyranosyl-(1 $\rightarrow 6)$-D-glucopyranoside], panose [ $\alpha$-D-glucopyranosyl-( $1 \rightarrow 6)$ - $\alpha$-D-glucopyranosyl$(1 \rightarrow 4)$-D-glucopyranoside], isomaltotriose, isomaltotetraose and isomaltopentaose) that are present in some foods or can be commercially prepared from starch. Their prebiotic effect derives from the fact that humans and other monograstric animals generally lack IMO-degrading enzymes. Glycogen is an a-glucan equivalent to starch but present in animals and it is characterized by being more extensively branched. Many bacteria, including lactobacilli (Goh and Klaenhammer, 2013), can synthesize and utilize this molecule as carbon storage.

Cellulose is the most abundant $\beta$-glucan present in nature. It is a key component of plant cell walls so that it accounts for the major proportion of fixed carbon in living organisms. Plant as well as fungal cell walls may contain other $\beta$-glucans with $\beta-1,3$ or multiple alternating $\beta-1,3$ and $\beta-1,4$ linkages and $\beta-1,6$ branching linkages. Similar to $\alpha$-glucans, some $\beta$-glucans can be produced by bacteria, including lactobacilli. Examples of these are the $\beta$ glucans produced by Lactobacillus suebicus ( $\beta-1,3$ linked) (Garai-lbabe et al., 2010) and L. brevis (Fraunhofer et al., 2017), where the glycosyl transferases catalyzing the synthetic process have been characterized.

\section{a-glucan metabolic pathways in Lactobacillus}

The $\alpha$-glucans are the substrates of a wide variety of hydrolytic enzymes. The $\alpha$-amylases cleave $\alpha-1,4$ linkages at any part of the polymers, whereas $\beta$ amylases act at the non-reducing ends liberating maltose ( $\alpha$-D-glucopyranosyl-( $1 \rightarrow 4)$-D-glucopyranoside). Pullulanases and amylopullulanases degrade $\alpha-1,6$ linkages and $\alpha-1,6$ as well as $\alpha-1,4$ linkages, respectively. Among pullulanases, isopullulanases and neopullulanases can be distinguished because they produce isopanose or panose from pullulan, respectively (Figure 5 ).

Lactobacilli usually encode multiple a-glycosidases in their genomes, mainly from the glycosyl hydrolase $(\mathrm{GH}) 13$ family (CAZy, Carbohydrate Active enZYmes classification; www.cazy.org), the family to which $\alpha$-amylases belong, although their specificities remain to be investigated in most cases. Among a-glucans, starch degradation by lactobacilli is relatively well characterized. The ability to degrade starch was noticed after the isolation and phenotypic characterization of new 
Lactobacillus strains from waste corn fermentations such as Lactobacillus amylophilus (Nakamura and Crowell, 1979) and Lactobacillus amylovorus (Nakamura, 1981). However, extracellular amylases are not common in this genus (less than $2 \%$ of all the GH13 glycosyl hydrolases present in lactobacilli). They are mainly concentrated in five species: L. acidophilus, L. amylovorus, Lactobacillus fermentum, L. plantarum and Lactobacillus manihotivorans (Petrova et al., 2013), although some particular strains belonging to different species can also degrade starch (e.g. Lactobacillus paracasei B41 (Petrova and Petrov, 2012)). In addition to amylases, pullulanases and amylopullulanases have been found in lactobacilli. $A$ thermostable pullulanase (endo- $\alpha-1,6$-glucosidase, GH13_14 subfamily) encoded by the LBA_1710 gene from L. acidophilus NCFM has been characterized. This enzyme preferentially acts on $\beta$ limit dextrins (amylopectins digested by $\beta$-amylases) over amylopectin (Møller et al., 2017). The product of LBA_1710 can also act on the linear polymer
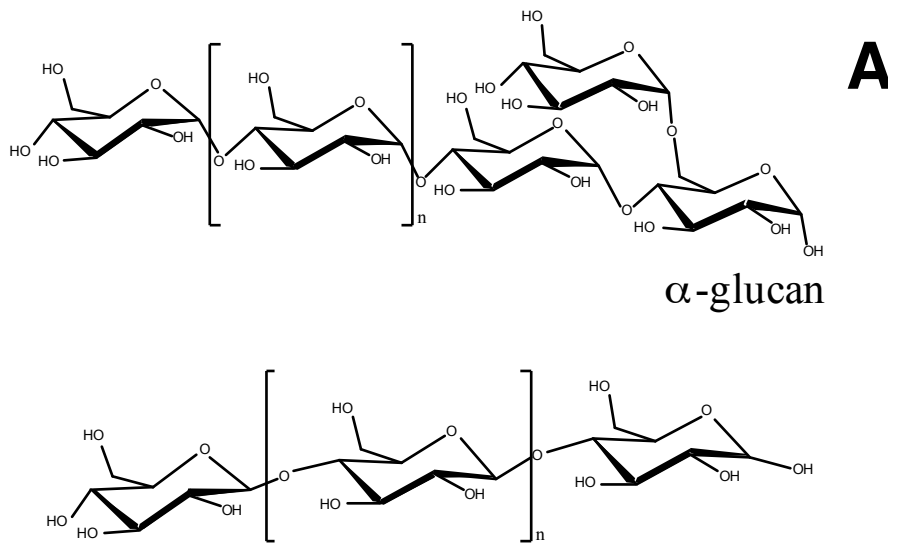

$\beta$-glucan

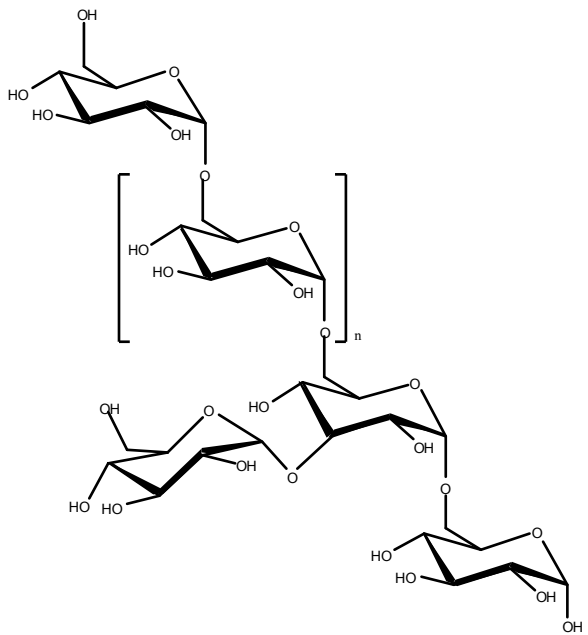

B

Dextran

Figure 4. A. Chemical structures of $\alpha$ - and $\beta$-glucans. An $\alpha-1,6$ ramification is represented in the structure of $\alpha-g l u c a n$. B. Chemical structure of dextran. An $\alpha-1,3$ ramification is represented. 
pullulan [(maltotriose- $\alpha 1,6$-maltotriose $\left.)_{n}\right]$ and possess a very low $\mathrm{K}_{\mathrm{m}}$ and very high specific activity for this polysaccharide. Notwithstanding, pullulan and amylopectine do not support growth of this strain. This would reflect the lack of $\alpha$-amylase activity and a non-efficient transport system for the resulting oligosaccharides after pullulanase digestion in this strain. The enzyme is secreted due to presence of a signal peptide and possesses two starch binding modules (CBM48), a catalytic domain (GH13_14 subfamily) and an additional surface- layer associated domain (SLAP) which warrants its retention at the cell surface. Homologues of this enzyme are present in many lactobacilli from intestinal origin. The enzyme may act on shortbranched $\alpha$-glucans derived from the degradation of dietary starch and glycogen by the human enzymes, supporting that these debranching enzymes play a role in the adaptation of these lactobacilli to the gut niche (Møller et al., 2017). An extracellular amylopullulanase from $L$. plantarum $L 137$, an isolate from a traditional fermented food containing fish and

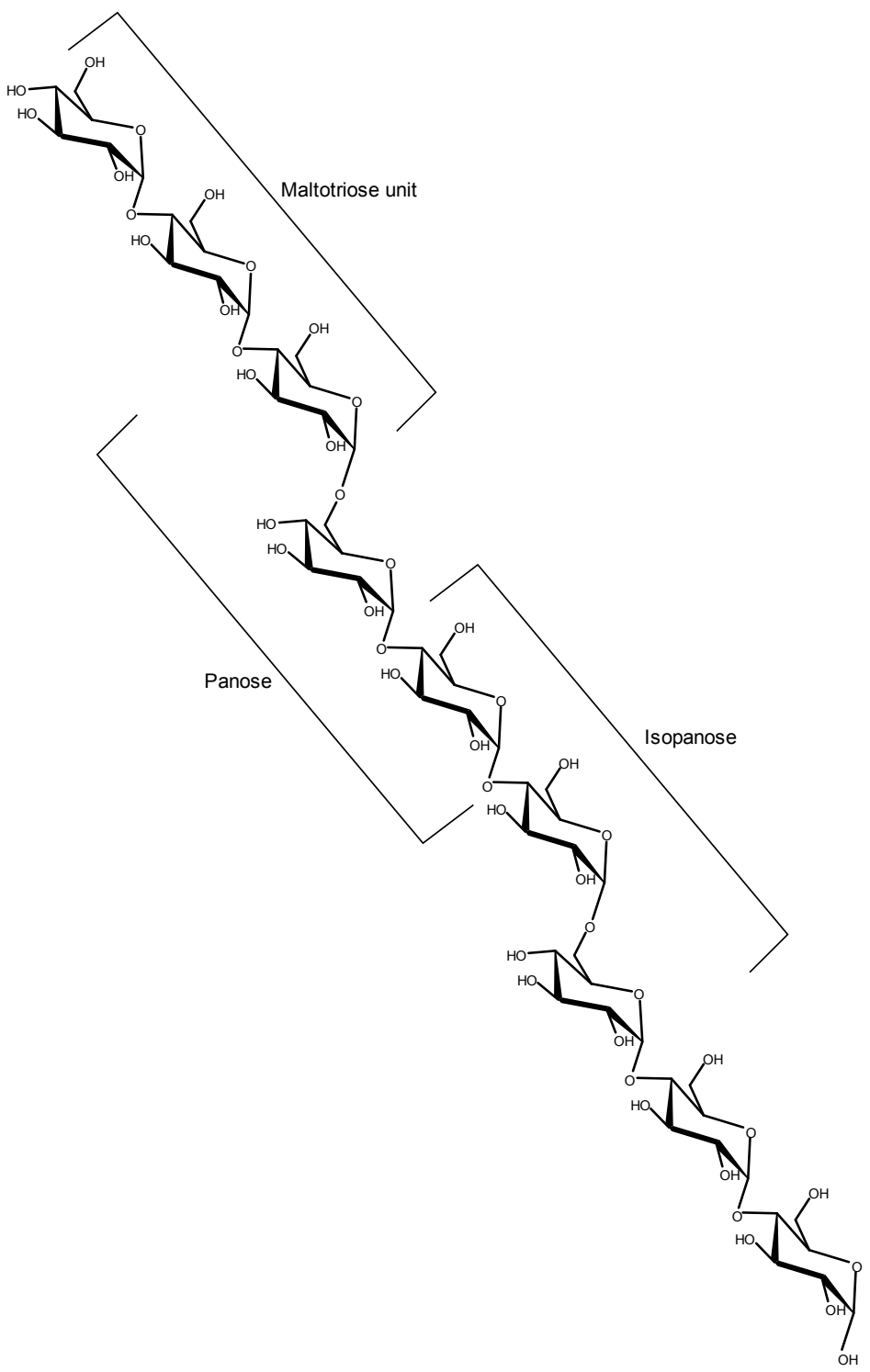

Figure 5. Chemical structure of pullulan. Maltotriose, isopanose and panose moieties are indicated. 
rice with high hydrolytic activity towards starch, has also been characterized. The enzyme degrades soluble starch to maltotriose and maltotetraose whereas it produces only maltotriose from pullulan (Kim et al., 2008). The encoding gene (apuA) is located in the endogenous plasmid pLTK13 (Kim et al., 2008). The enzyme contains a number of amino acids repeats at the $\mathrm{N}$ - and $\mathrm{C}$-terminus that are derived from the same repeated DNA sequence (5'ACCGACGCAGCCAACTCA-3') but translated in different frames. The C-terminal repeats are similar to mucin-binding domains present in bacterial peptidoglycan-bound proteins and most probably participate in substrate binding (Kim et al., 2008). Domains with amino acid repeats are typically found in carbohydrate degrading enzymes. The amylases from $L$. amylovorus, $L$. plantarum and $L$. manihotivorans carry a C-terminal starch-binding domain (SBD) of almost 500 amino acids consisting of tandem repeat units of 91 amino acids in variable numbers (Morlon-Guyot et al., 2001). SBDs promote attachment to the substrate and allow degradation of non-soluble starch (Rodriguez Sanoja et al., 2000). A neopullulanase has been cloned and characterized from Lactobacillus mucosae LM1 (Balolong et al., 2016). A homologous gene had been previously shown to be induced in the amylolytic $L$. plantarum A6 strain during pearl millet fermentation and neopullulanase activity detected (Humblot et al., 2014).

A number of enzymes involved in the degradation of IMOs encoded by lactobacilli have also been characterized. A glucan- $\alpha-1,6$-glucosidase (GH13_31 subfamily) encoded by the $L$. acidophilus NCFM gene LBA_0264 is involved in the catabolism of IMO (Møller et al., 2012). The participation of glucan-a1,6-glucosidase and maltose phosphorylase (see below) have also been implicated in the catabolism of IMO in L. brevis $(\mathrm{Hu}$ et al., 2013). The $L$. acidophilus NCFM enzyme is induced after growth in IMO mixtures, displays a high activity on panose and prefers IMO with more than two glucoses, as it acts preferentially on isomaltotriose and isomaltotetraose compared to isomaltose. The LBA_0264 genes and its homologues in other lactobacilli are not clustered with other sugar catabolism or sugar transporter genes except for Lactobacillus johnsonii ATCC 33200 and Lactobacillus gasseri JV-V03, which belong to the acidophilus group and where the IMOutilizing gene forms part of the maltodextrin operon (Møller et al., 2012), and in other Lactobacillus species such as Lactobacillus casei (Monedero et al., 2008). Another $\mathrm{GH} 13$ 13 enzyme has been characterized in L. plantarum LL441. It displays activity on isomaltose and isomaltulose [a-Dglucopyranosyl-( $1 \rightarrow 6)$-D-fructofuranoside], but not on panose or isomaltotriose, and its gene is clustered with genes encoding EIIABCD components of a mannose-class PTS (Delgado et al., 2017). Whether the enzyme might be acting on phosphorylated disaccharides needs to be proven.

\section{Metabolism of maltodextrins}

Utilization of maltodextrins (linear oligosaccharides derived from starch hydrolysis) is a characteristic more extended in lactobacilli. Species adapted to starch-rich environments (e.g. plant material fermentations where the endogenous plant amylases release maltose and maltodextrins) such as Lactobacillus sanfranciscensis, participating in sourdough fermentations during bread making, are particularly efficient in maltose and maltodextrin utilization. The enzymatic machinery for the utilization of these carbohydrates in lactobacilli soon attracted attention and it has been thoroughly investigated. In the 90's maltose catabolic proteins were partially characterized in $L$. sanfranciscensis DSM20451 (Ehrmann and Vogel, 1998) and Lactobacillus brevis ATCC 8287 (Huwel et al., 1997). These microorganisms relied on an intracellular maltose phosphorylase (MapA [EC 2.4.1.8]) non requiring pyridoxal 5'-phosphate and belonging to the $\mathrm{GH} 65$ family, which also includes trehalose phosphorylases (EC 2.4.1.64), and kojibiose phosphorylases (EC 2.4.1.230), for catalyzing a phosphorolysis of the disaccharide that involves an inversion of the anomeric configuration of the $\mathrm{C}-1$ atom, giving $\beta$-glucose 1-phosphate and glucose. $\beta$-glucose 1 -phosphate is further converted to glucose 6-phosphate for its incorporation into glycolysis via $\beta$-phosphoglucomutase (Pgm), whose gene is co-localized in the chromosome with mapA (Figure 6). MapA displays a high specificity for maltose, but it is not active on maltodextrins such as maltotriose or maltotetraose and it cannot phosphorolyse disaccharides with other $\alpha$-linkage configurations such as isomaltose $(\alpha-1,6)$, nigerose $(\alpha-1,3)$, kojibiose $(\alpha-1,2)$ or trehalose $(\alpha-1,1)$. Furthermore, it differs in sequence from other maltose (maltodextrin) phosphorylases such as that of $E$. coli (GT35 family). MapA is a dimer in solution and its structure has been solved for the $L$. brevis enzyme (Egloff et al., 2001). The structure consists of a $\beta$ sandwich domain linked to an $(\alpha / \alpha)_{6}$ barrel catalytic domain, and a C-terminal $\beta$ sheet domain. The $(\alpha / \alpha)_{6}$ barrel domain displays striking structural and functional similarities to the catalytic domain of a glucoamylase from Aspergillus awamori, 
suggesting evolution from a common ancestor (Egloff et al., 2001). In the structures of these enzymes the catalytic conserved Glu residue from the glucoamylase superposes onto a conserved Glu of MapA that likely acts as the acid catalytic residue that promotes the nucleophilic attack of phosphate on the glycosidic bond. Modelling of the $L$. acidophilus MapA protein with different substrates allowed understanding why this enzyme does not accommodate maltotriose or maltotetraose in its active site (Nakai et al., 2009). The protein adopts a configuration where loop His413-Glu421 between $\alpha 3$ and $\alpha 4$ of the $(\alpha / \alpha)_{6}$ barrel domain blocks the binding of longer malto-oligosaccharides. However, this enzyme has been applied in reverse phosphorolysis reactions for the synthesis of $\alpha-1,4-$ linked disaccharides with $\beta$-glucose 1-phosphate as donor and glucose, glucosamine, $N$-acetyl glucosamine, L-fucose, mannose or xylose as acceptors; being unable to use other sugars with axial hydroxyls at $\mathrm{C}-3$ and $\mathrm{C}-4$ positions or disaccharides/trisaccharides (Nakai et al., 2009).

A genome survey of 38 Lactobacillus strains revealed that the presence of a set of genes for maltodextrins utilization, including mapA and pgm,

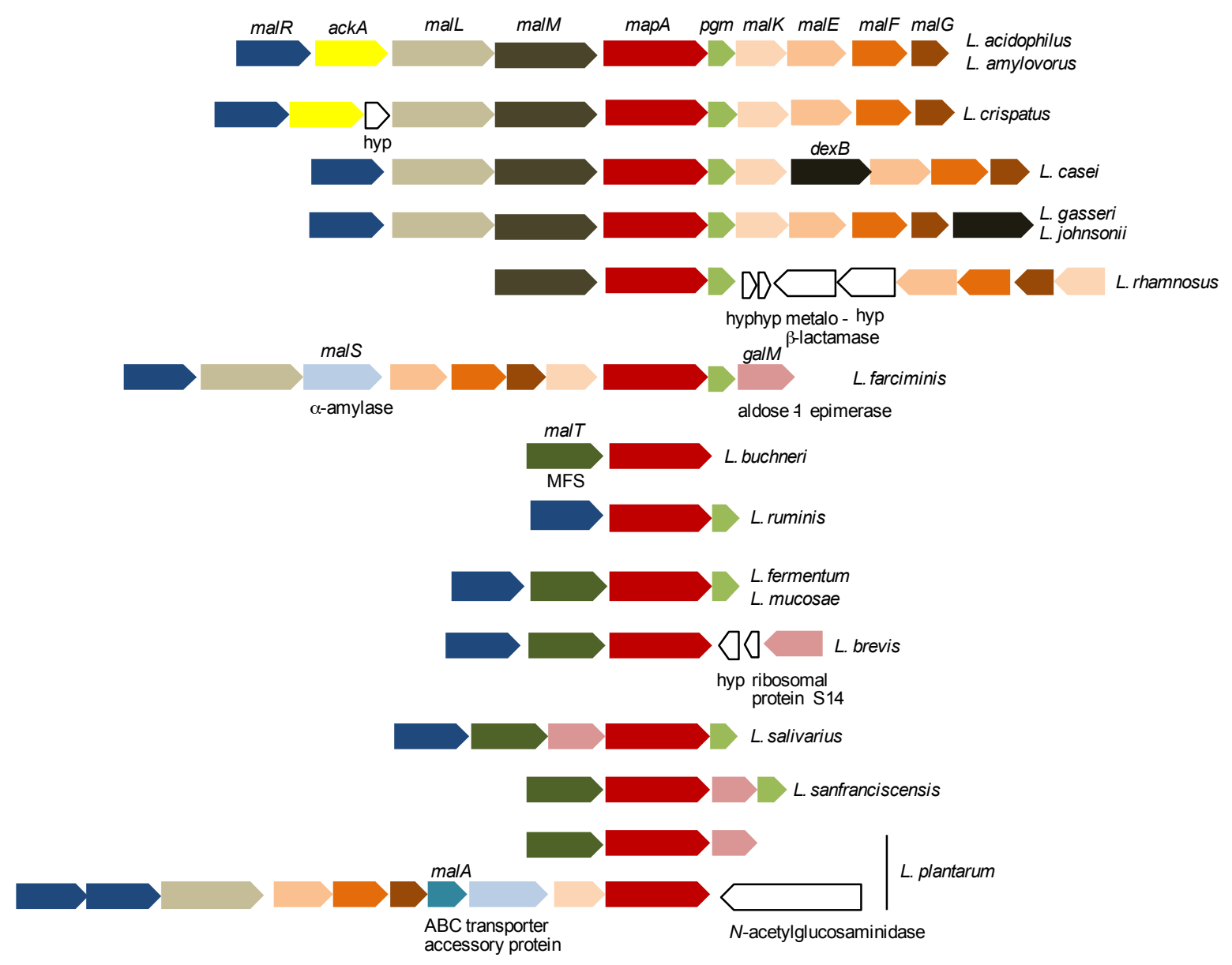

Figure 6. Comparison of maltose/maltodextrin operons in Lactobacillus species. The genetic organization of the operons encoding the enzymes and transporters for maltose/maltodextrin utilization in selected lactobacilli is depicted. The maltose/maltodextrin locus in Lactobacillus species carry genes for a specific $A B C$ transporter, maltose phosphorylase and $\beta$-phosphoglucomutase together with several a-glycosidases or a MFS permease, maltose phosphorylase, $\beta$-phosphoglucomutase and, generally, an aldose 1-epimerase. In L. plantarum strains both types of mal operons are simultaneously present. Colors indicate homologous genes. Arrows indicate directionality. 
is widespread in lactobacilli. These gene clusters usually include different a-glycosidases, although the presence of amylases is scarce (Ganzle and Follador, 2012). The maltodextrin operon which contain the mapA and pgm genes have been genetically characterized in $L$. acidophilus (Nakai et al., 2009) and L. casei (Monedero et al., 2008), showing that in these species maltodextrin transport is carried out by an ABC transporter (MalEFGK 2 ) homologous to that of the well-studied maltose/ maltodextrin transporter of $E$. coli (Figure 6). In $L$. casei BL23, ten mal genes are clustered and cotranscribed in a single mRNA whose expression is regulated by MaIR, a transcriptional regulator of the Lacl/GalR family and repressed by the presence of glucose via the general CCR mechanism mediated by the global regulator CcpA. According to studies conducted with Streptococcus pneumoniae MalR, this regulator acts as a transcriptional repressor and maltose strongly inhibits its DNA binding capacity (Puyet et al., 1993). Cis-acting sequences recognized by MalR can be identified adjacent to the -10 and -35 promoters of the $L$. acidophilus and Lactococcus lactis mal operons (Nakai et al., 2009). In addition to the maltose phosphorylase and phosphoglucomutase genes, three $\alpha$-glucosidase-encoding genes $(\mathrm{GH} 13)$ are clustered together with the $L$. casei maltosecatabolic genes: malL, encoding a putative oligoa1,6-glucosidase (putatively acting on short IMO like isomaltose); malM, encoding a maltogenic $\alpha$ amylase (cuts $\alpha-1,4$ linkages from dextrins yielding maltose) and $\operatorname{dex} B$, coding for a second $\alpha-1,6$ glucosidase (Monedero et al., 2008). This last enzyme belongs to the $\mathrm{GH} 13$ 31 subfamily (glucana-1,6-glucosidase) and, as described before, based on the studies of its $L$. acidophilus counterpart is able to degrade IMO. Therefore, it is postulated that in addition to maltodextrins, the $\mathrm{ABC}$ transporter MalEFGK $_{2}$ would be able to transport IMO. A second operon located in opposite direction encodes an additional $A B C$ transporter with high homology to MalEFGK 2 but its function is unknown and mutations in their genes have no phenotypic effects on maltose or maltotriose growth. In other $L$. casei strains, such as ATCC 334 , maltodextrin utilization is impaired by a large deletion in the mal cluster (Monedero et al., 2008).

The mal operon of $L$. acidophilus NCFM consists of nine genes and a malR regulator (Nakai et al., 2009). In addition to the maltodextrin ABC transporter, MapA and Pgm, L. acidophilus encodes two glycosidases: a maltogenic a-amylase (MalM) and an oligo $\alpha-1,6$-glucosidase (MalL) that are homologous to their $L$. casei counterparts. The $L$. acidophilus mal operon also carries an acetate kinase gene (ackA) involved in pyruvate metabolism during glycolysis. Although $A B C$ transporters can be identified as the main maltodextrin transport systems in lactobacilli, in some species that efficiently use maltose as a carbon source a genetic association of a gene encoding a permease of the major facilitator superfamily (MFS) is found with $m a p A$ and pgm genes (Figure 6). This suggests that these species (e.g. L. sanfranciscensis, $L$. salivarius, $L$. brevis) make use of a maltose- $\mathrm{H}^{+}$ symport system for the uptake of the disaccharide. In contrast, no PTS systems for the transport of maltose similar to those described in Bacillus subtilis have been identified in lactobacilli. Studies on the maltose uptake in $L$. sanfranciscensis LTH2581, a strain which only ferments maltose and glucose, confirmed the presence of a maltose- $\mathrm{H}^{+}$ symport system. When maltose is taken up by this strain the intracellularly generated glucose exceeds the metabolic capacity of the cells, which results in glucose expulsion through a glucose uniport system (Neubauer et al., 1994). In lactobacilli utilizing maltose through a MFS permease, a genetic association of the mal cluster with a gene encoding an aldose 1-epimerase (EC 5.1.3.3) can be found (Figure 6). This enzyme is involved in the anomeric conversion of D-glucose between the $\alpha$ and $\beta$ forms, which possibly speeds up the entry of glucose into the glycolytic pathway via its phosphorylation by glucokinase. Strains of $L$. plantarum are remarkable by the fact that they carry two mapA and pgm genes. One couple is linked to an $A B C$ transporter (MalEFGK ${ }_{2}$ ) and $\alpha$-glucosidases (mal cluster 1), whereas the other forms a cluster (mal cluster 2) with a MFS permease (Figure 6). Therefore, strains of this species possess the capacity to use maltose and maltodextrins by using two separated sets of genes. Unlike the rest of lactobacilli, the $L$. plantarum mal cluster 1 contains two transcriptional regulators (genes Lp_0172 and Lp_0173) with homology to MalR (Muscariello et al., 2011). Expression of malE from this cluster is induced by maltose and repressed by glucose via CcpA. Mutational analysis suggested that only the product of Lp_0173 participated in malE regulation. A mutant in this gene showed a glucose-insensitive expression of malE together with a lack of induction by maltose (Muscariello et al., 2011). Remarkably, an in silico approach for the study of Lacl-GalR transcriptional regulators in L. plantarum WCFS1 identified five operons putatively controlled by the products of Lp_0172 and Lp_0173 which include the mal1 and mal 2 clusters, an operon for $\beta$-glucosides 
utilization, an operon carrying the genes for teichoic acid synthesis tagB1 and tagB2 and an amino acid permease (Francke et al., 2008).

Transport studies with ${ }^{14} \mathrm{C}$-maltose has revealed an unusually high $\mathrm{K}_{m}$ for the $L$. casei maltose $A B C$ transporter (around $0.3 \mathrm{mM} ; \mathrm{K}_{\mathrm{m}}$ for $A B C$ transporters and their substrates are usually in the $\mu \mathrm{M}$ range), which suggested that maltose is not the preferred substrate and points to maltodextrins as the natural oligosaccharides taken up by this transporter (Monedero et al., 2008). This notion is further substantiated by the fact that the three glycosidase enzymes encoded by the mal cluster are intracellular. Therefore, in this microorganism maltodextrins are preferentially metabolized over maltose, and they are hydrolyzed in the cytoplasm to render maltose and glucose. This characteristic is probably shared by the rest of lactobacilli harboring maltodextrin clusters with $\mathrm{ABC}$ transporters. In vitro studies on the binding capacity of the solute binding component of the maltodrextrin $\mathrm{ABC}$ transporter from $L$. casei (MalE) revealed that it is able to interact with maltotriose, maltotetraose, maltopentaose and with $\alpha, \beta$ and $\gamma$-cyclodextrins, which carry six, seven and eight glucose molecules, respectively, with $K_{d}$ values that were in the $\mu \mathrm{M}$ range, albeit showing a preference for linear maltodextrins over cyclodextrins (Homburg et al., 2017). However, contrarily to E. coli MalE, the solute binding component of the $L$. casei maltose system does not interact with maltose. The fact that mutants in the $L$. casei malK gene are not able to ferment maltose (Monedero et al., 2008) suggests that other solute binding protein may be responsible to recognize and deliver maltose intracellularly via the MalFG permease component of the ABC system. Alternatively, it cannot be excluded that the MalK ATPase component of the transporter can be shared by an as yet unidentified and incomplete maltose-specific $A B C$ system lacking a cognate ATPase unit (Homburg et al., 2017). Crystallographic data of $L$. casei MalE complexed with maltotriose, maltotetraose and cyclodextrins provided structural clues for its lack of interaction with maltose (Homburg et al., 2017). The globular carbohydrate-binding protein MalE consists of two $\mathrm{N}$ - and $\mathrm{C}$-terminal domains which form a ligandbinding pocket situated between them, a characteristic shared by other MalE homologues. However, in L. casei MalE three aromatic residues from the C-terminal domain (W234, Y164 and W353) stack against a specific glucose moiety of the bound substrate and create three distinct subpockets, where the position of three glycosidic moieties is fixed with additional hydrogen bonds from the $\mathrm{N}$-terminal MalE domain. Thus, the disaccharide maltose cannot adequately accommodate the three subpockets, preventing MalE to adopt the closed conformation that is achieved after interaction with linear and cyclic dextrins. This observation is also confirmed by the fact that, contrarily to maltotetraose, maltose does not stimulate ATPase activity of the MalEFGK 2 complex (Homburg et al., 2017).

Transcriptomic data under laboratory or natural fermentation conditions has shed some light on the regulation of the expression of glucans/starch utilizing enzymes and their concerted action during the degradation of these carbohydrates by lactobacilli. Experiments with $L$. acidophilus NCFM show that this strain induces preferentially the expression of PTS transport systems in the presence of prebiotic glucans such as cellobiose $[\beta$ D-glucopyranosyl-(1 $\rightarrow 4)$-D-glucopyranoside], isomaltose, panose or gentiobiose [ $\beta-D$ glucopyranosyl-( $1 \rightarrow 6)$-D-glucopyranoside], whereas polydextrose (a synthetic glucose polymer consisting of a mixture of different a-glycosidic linkages) induces $A B C$ transporters (Andersen et al., 2012). Transport via the PTS results in intracellular phosphorylated sugars that can be cleaved by different phospho-glucosidases. As expected, MapA was also induced by polydextrose. Of note, MalH, a isomaltose 6-phosphate hydrolase (GH4) encoded by LBA_1689 was induced by isomaltose, isomaltulose, panose and polydextrose. This enzyme participates in the formation of glucose 6-phosphate and glucose from isomaltose 6phosphate but also glucose 6-phosphate plus fructose from isomaltulose internalized via a PTS encoded by the LBA_0606-LBA_0609 locus (Andersen et al., 2012). MalH has been found in lactobacilli associated to the gastrointestinal tract and it could be a good indicator of prebiotic activity of $\alpha-1,6$ glucosides such as panose and polydextrose that can in addition be degraded by the activity of the product of LBA_0264, a glucan$\alpha-1,6$-glucosidase (GH13_31) which is induced by IMO (Andersen et al., 2012). Expression of genes involved in starch metabolism in L. plantarum A6 has been studied during a natural fermentation of pearl millet porridge (Humblot et al., 2014). This highly amylolytic strain expresses a-amylases (intracellular and extracellular), a-glucosidase, neopullulanase, amylopectin phosphorylase and MapA when growing in this natural substrate. The ability of this strain to liquefy the pearl millet gruel compared to other L. plantarum strains that do not 
grow in this substrate is attributable to the presence of the extracellular $\alpha$-amylase (amyA). Metatranscriptomic analyses during the spontaneous fermentation by natural microbial consortia of different sourdoughs (wheat and spelt) with backslopping for ten days have been carried out (Weckx et al., 2011). By using a DNA microarray carrying genes from several lactic acid bacteria, a high expression of glycolytic enzymes was observed during these fermentations. However, the expression of mapA and maltose/maltodextrins $A B C$ transporter encoding genes was low in both sourdough types and it corresponded mainly to the L. plantarum and Lactococcus lactis genes, respectively; even though the microarray also carried genes from $L$. sakei, $L$. curvatus, $L$. brevis, and L. fermentum (Weckx et al., 2011). These expression levels were related to the concentration of maltose throughout the back-slopping process. The sourdough microbiota was capable of degrading other carbohydrates important in sourdough (e.g. saccharose and fructose) and their metabolism could cause CCR of the utilization of other carbon sources mediated by $\operatorname{CcpA}$, whose gene is highly expressed during sourdough fermentations (Weckx et al., 2011).

\section{Metabolism of glycogen}

Lactobacilli carry in their genomes gene clusters for the biosynthesis of the storage polysaccharide glycogen. In some lactobacilli that dwell in specific mucosal niches, such as the vagina, glycogen metabolism has been associated to their proliferation (Miller et al., 2016). Glycogen metabolic genes have been characterized in $L$. acidophilus and it is postulated that they play a role in the persistence of this bacterium in the gut (Goh and Klaenhammer, 2013). The bacterial glycogen synthesis starts by the synthesis of ADP-glucose from glucose 1-phosphate by GlgC or GlgD enzymes. Then the glycogen synthase (GlgA) transfers glucose from ADP-glucose to a chain of a-1,4-glucan, whereas GlgB is involved in the formation of the $\alpha-1,6$ branching points. For its catabolism, glycogen phosphorylase (GlgP) catalyzes the breakdown of $\alpha-1,4$ linkages and $\mathrm{Glg} X$ participates in the debranching at the $\alpha-1,6$ bonds in dextrins that cannot be further processed by GlgP. In $L$. acidophilus NCFM the glycogen cluster encompasses $11.7 \mathrm{~kb}$ and carry glgBCDAP together with two genes coding for a $\alpha$-amylase and $\beta$ phosphoglucomutase (Goh and Klaenhammer, 2013). Similar genetic structures are found in approximately one third of the sequenced Lactobacillus, being mainly present in strains associated to the gastrointestinal tract of mammals and other animals. As an example, although the cluster is present in human intestinal isolates of $L$. bulgaricus and $L$. helveticus, it is not found in dairy isolates of these species (Goh and Klaenhammer, 2013). Expression of the $L$. acidophilus glg genes depends on the carbon source and the growth phase, showing maximal expression with raffinose [a-D-galactopyranosyl-( $1 \rightarrow 6)$ - $\alpha$-D-glucopyranosyl$(1 \rightarrow 2)-\beta-D$-fructofuranoside] and repression by glucose. As the enzymes for the synthesis and degradation are produced in parallel, the regulation of intracellular glycogen levels depending on the carbon sources may rely on the carbon fluxes. Mutants impaired in $g \lg A$ or $g \lg B$ present a reduced growth on raffinose and a mutant in $g \lg B$ and in the gene encoding the catabolic glycogen phosphorylase ( $g l g P$ ) grows slower in MRS medium (containing glucose) and are less resistant to simulated gastrointestinal conditions (Goh and Klaenhammer, 2013). This suggests that the accumulation of a-glucan polymers with sequestered glucose that cannot be further metabolized results in impaired growth. This highlights the need for co-ordinated glycogen synthesis and degradation for retrieving glucose from glycogen storage under normal and stress conditions. In vivo experiments in a germ-free mice model in which wild-type $L$. acidophilus and its $g l g A$ mutant were delivered to animals by intragastric gavage showed that the wild-type strain was able to compete and to displace the glgA mutant in monocolonized mice. This demonstrated the role of glycogen synthesis and utilization in lactobacilli in competitive fitness in the gut (Goh and Klaenhammer, 2014).

\section{$\beta$-glucan metabolic pathways in Lactobacillus}

Despite the fact that lactobacilli are usually associated with the microbiota of plant decaying material, cellulases (endo- $\beta-1,4-D$-glucanases) have not been described for this genus and in general, for the lactic acid bacteria. Notwithstanding, the prebiotic activity of some $\beta$-glucans has been established but the metabolism of these polymers by lactobacilli has been rarely demonstrated. Very few examples of growth stimulation effects of $\beta$ glucans in lactobacilli are found in the literature, and they have mainly proved by using $\beta$-glucan hydrolysates (Dong et al., 2017).

Important efforts have been made to use lactobacilli for the conversion of lignocellulosic material by applying saccharolytic processes prior fermentation or by the use of engineered strains expressing $\beta$-D- 
glucanases from other microbial sources (Moraïs et al., 2014; Okano et al., 2010; Overbeck et al., 2016). Similarly, lactobacilli expressing $\beta$ glucanases from other sources have been engineered for fermentation or health promoting effects (Liu et al., 2005; Wang et al., 2014a).

\section{Metabolism of xylooligosaccharides}

\section{Structural characteristics of xylooligosaccharides}

Xylooligosaccharides (XOS) are plant-derived oligosaccharides with $\beta-1,4$ linkages between xylose (a pentose) monomers that can be decorated with residues of the pentose arabinose. These residues can be linked by $\alpha-1,2$ or $\alpha-1,3$ bonds to xylose molecules along the chain (arabinoxylan oligosaccharides) where one or two arabinose residues can be found per xylose. These polymers are abundant in plant cell walls and together with other heteropolysaccharides form the hemicellulose component in plants.

\section{Xylooligosaccharides metabolic pathways in Lactobacillus}

In vitro growth assays and studies of the microbiota of humans concluded that these polysaccharides possess a prebiotic effect that stimulates the growth of bifidobacteria (Childs et al., 2014; Lin et al., 2016). This is supported by the characterization of multiple $A B C$ transporters for XOS and XOSdegrading enzymes in species of Bifidobacterium (Ejby et al., 2013). In vitro growth assays and human trials which explored changes in gut microbiota composition after XOS intake also pointed to XOS as prebiotic polysaccharides that stimulate growth of certain lactobacilli (Lin et al., 2016). Notwithstanding, the capacity to ferment XOS by lactobacilli seems to be limited (Ananieva et al., 2014). In accordance to this, the information about enzymes degrading XOS and arabinoxylans in lactobacilli is scarce. Two different enzymatic activities are needed to completely degrade arabinoxylans: arabinofuranosidase (liberating the arabinose residues that decorate the xylooligosaccharide backbone) and $\beta$-xylosidase (acting on the $\beta-1,4$ linkage between xylose molecules). Enzymes with this activity are classified into $\mathrm{GH} 43$ and GH51 glycosyl hydrolase families. L. brevis is thus far the only Lactobacillus species in which these activities have been studied (Michlmayr et al., 2013; Michlmayr et al., 2011). This species can be found in a wide variety of habitats including fermentations of hemicellulose-rich plant materials. Three GH43 $\beta$-xylosidases and two GH51 arabinofuranosidases have been found during the study of the genomes of several strains. The sequences of these enzymes show a high level of amino acid identity to enzymes from typical intestinal bacteria (e.g. bifidobacteria), suggesting events of horizontal gene transfer at the intestinal niche. The $\mathrm{GH} 43$ enzymes from $L$. brevis DSM 20054, annotated as $\beta$-xylosidases, have been thoroughly characterized (Michlmayr et al., 2013). The $\beta$-xylosidase encoded by LVIS_0375 (xynB1) gene exhibited activity towards $\beta-1,4$-xylobiose and $\beta-1,4-x y l o t r i o s e . ~ L V I S \_2285$ (xynB2) showed low activity with $p$-nitrophenyl- $\beta$-D-xylopyranoside and no activity with $\beta-1,4-x y l o o l i g o s a c c h a r i d e s$, whereas the $\beta$-xylosidase encoded by LVIS_1748 (abf3) exhibited activity for $\alpha-1,5$-arabinooligosaccharides. XynB1 and XynB2 are 32\% identical and are also present in strains of Lactobacillus buchneri, $L$. fermentum, Lactobacillus hilgardii, L. pentosus and $L$. reuteri. These species belong to the group of heterofermentative lactobacilli so that it has been postulated that the capacity to degrade XOS and arabinoxylans is restricted to this particular group within lactobacilli (Michlmayr et al., 2013). Unlike the arabinofuranosidases Abf1 and Abf2 characterized from L. brevis DSM 20054 (GH53) (Michlmayr et al., 2011), Abf3 (and XynB1 and XynB2) cannot release arabinose from arabinoxylans with a composition of $65 \% \quad \alpha-1,3$-linked arabinose, $8 \% \quad \alpha-1,2$-linked arabinose and $26 \%$ doubly substituted xylose (two arabinose linkages per xylose monomer) indicating that these enzymes do not act as arabinofuranosidases. Furthermore, Abf1 and Abf2 are selective for $\alpha-1,3$-linked arabinose residues of monosubstituted xylose (Michlmayr et al., 2011).

The degradation of other hemicelluloses such as xyloglucan (a $\beta-1,4$ glucan backbone with xylose residues linked to glucose via $\alpha-1,6$ bonds) by lactobacilli has received less attention. $L$. pentosus MD353, isolated from cucumber fermentation, carries a xylose operon (xyIAB) involved in the metabolism of this pentose and encoding a xylose isomerase $(x y / A)$ and xylulose kinase $(x y / B)$ (Lokman et al., 1991). These enzymes convert cytoplasmic D-xylose to D-xylulose 5-phosphate, an intermediate of the pentose phosphate pathway. Adjacent to this operon two genes are present, $x y I P Q$, which are also induced by xylose via the xylose repressor XyIR. XyIQ is a GH31 a-xylosidase which has been demonstrated to act on isoprimeverose ( $\alpha$-D-xylopyranosyl- $(1 \rightarrow 6)$-Dglucopyranoside) and it is also able to liberate with very low efficiency small amounts of xylose from xyloglucan oligosaccharides with different linkage configurations (Chaillou et al., 1998). Isoprime- 
verose is usually released from xyloglucan by cellulolytic microorganisms producing endoglucanases and it can be taken up by $L$. pentosus via the product of $x y I P$. This gene encodes a galactoside-pentoside-hexuronide family transporter that catalyzes the transport of isoprimeverose, but not xylose, through a proton motive force-driven process (Heuberger et al., 2001).

\section{Metabolism of galactooligosaccharides}

Structural characteristics of galactooligosaccharides $\beta$-galacto-oligosaccharides (GOS) are nondigestible carbohydrates usually composed of lactose at the reducing end and one to ten galactose units linked by $\beta-1,3, \beta-1,4$ or $\beta-1,6$ bonds (Macfarlane et al., 2008). They can be acquired naturally through the diet from the degradation of galactan side chains of the rhamnogalacturonan I fraction of pectin (Jones et al., 1997). In addition, they are also incorporated as prebiotics after their synthesis by the transgalactosylation activity of $\beta$ galactosidases on lactose, which acts both as donor and as acceptor of the galactose moiety (Vera et al., 2016). Analysis of some GOS mixtures revealed the presence of oligosaccharides with galactose at the reducing end instead of glucose, and they may also contain disaccharides different from lactose that are considered GOS as well. Indeed, commercial GOS are typically mixed-length galactosylated compounds with a DP ranging from 2 to 12 (Coulier et al., 2009). The type of linkage, mostly $\beta-1,3, \beta-1,4$ and/or $\beta-1,6$, and to a lesser extent, $\beta-1,2$, is determined by the enzyme source. Commercial enzymes used for GOS synthesis belong to the CAZy glycosyl hydrolase family $2(\mathrm{GH} 2)$ and they are obtained from Bifidobacterium bifidum and Bacillus circulans for GOS with $\beta-1,3$ and $\beta-1,4$ bonds, respectively, and from Kluyveromyces lactis and Aspergillus oryzae to obtain $\beta-1,6$ linked GOS (Rodriguez-Colinas et al., 2011). Most of the published studies use the term GOS when referring to $\beta$-GOS, but there are also GOS with $\alpha$ configuration, which are produced by transgalactosylation reactions with $\alpha$-galactosidases (Wang et al., 2014b). The oligosaccharides 3'-, 4'and 6'-galactosyllactose have been found in colostrum and human milk, and they constitute the only oligosaccharides contained in common between human milk oligosaccharides (HMOs) and GOS.

GOS are metabolized by specific bacteria in the gastrointestinal tract, and they have been found to modulate the gut microbiota by stimulation of beneficial bacteria such as bifidobacteria and lactobacilli, and inhibition of pathogenic bacteria (Macfarlane et al., 2008; Rastall et al., 2005). The fermentation of GOS in the gastrointestinal tract leads to an increased production of specific short chain fatty acids (SCFA), which are known for their health benefits including reduction of the risk of developing cancer and intestinal disorders (Cardelle-Cobas et al., 2009; Sangwan et al., 2011).

\section{GOS metabolic pathways in Lactobacillus}

Lactobacillus species in general can efficiently utilize GOS, although their utilization is a straindependent character and it may also vary depending on GOS DP (Endo et al., 2016; Thongaram et al., 2017). A study on GOS utilization by different species of Lactobacillus showed that 9 out of 10 tested species metabolized the galactosyllactose fraction (35\%) of a GOS mixture to a different degree (Endo et al., 2016). All tested strains of $L$. delbrueckii, $L$. plantarum, $L$. fermentum, $L$. reuteri, L. johnsoni and $L$. acidophilus metabolized galactosyllactose whereas only some strains of $L$. rhamnosus, $L$. paracasei and $L$. sakei did it. As with fructans, the availability of genomic sequences allowed the determination of the genetic basis of GOS metabolism by lactobacilli. In this way, transcriptomic analyses of $L$. acidophilus NCFM with whole-genome DNA microarrays, revealed that GOS induce the lac-gal gene cluster, which encodes a galactoside-pentose-hexuronide permease (LacS), two $\beta$-galactosidases belonging to the $\mathrm{GH}$ family 42 (LacA) and GH family 2 (LacLM), and enzymes of the Leloir Pathway (GalM, GalT, GalK and GaIE) involved in the metabolism of galactose (Andersen et al., 2011). Inactivation of LacS impaired growth on lactose, lactitol and GOS (Andersen et al., 2011). Phylogenetic analysis showed that lacS is mainly found in human gutassociated Lactobacillus species, suggesting that transport and catabolism of those carbohydrates could be a significant energy source for lactobacilli in the gut (Andersen et al., 2011). Possibly, GOS are transported into the cells by the LacS permease, hydrolyzed by the $\beta$-galactosidases LacA and LacLM into galactose and glucose, which would be directed to the Leloir Pathway and glycolysis, respectively. Interestingly, the lac-gal cluster is also induced by bile acids (Barrangou et al., 2006; Pfeiler et al., 2007), suggesting that bile may act as a location signal in the gut environment where GOS and related carbohydrates would be readily available. 
L. fermentum is able to utilize a-GOS as carbon source for growth in soymilk (LeBlanc et al., 2004). This capability relies in the expression of the gene $m e l A$, that encodes an $\alpha$-galactosidase with activity on $\alpha-1,6$ linkages (Carrera-Silva et al., 2006). aGOS such as raffinose ( $\alpha$-D-galactopyranosyl$(1 \rightarrow 6)-\alpha-D$-glucopyranosyl-( $1 \rightarrow 2)-\beta-D$-fructofuranoside), and stachyose ( $\alpha-D$-galactopyranosyl$(1 \rightarrow 6)$ - $\alpha$-D-galactopyranosyl-( $1 \rightarrow 6)-\alpha-D$ glucopyranosyl-( $1 \rightarrow 2)-\beta$-D-fructofuranoside), are abundant in vegetables and they are substrates for MelA. Other $\alpha$-galactosidases that hydrolyze those a-galactosides were also identified in $L$. plantarum (Silvestroni et al., 2002) and L. reuteri (Tzortzis et al., 2003). The growth of $L$. acidophilus NCFM in the presence of stachyose induced a cluster of genes encoding an ATP-binding cassette (ABC) transporter, a GH36 a-galactosidase and enzymes from the Leloir Pathway. Inactivation of the $\alpha$ galactosidase-encoding gene resulted in the loss of the ability to grow on raffinose, stachyose and the disaccharide melibiose ( $\alpha$-D-galactopyranosyl$(1 \rightarrow 6)$-D-glucopyranoside) (Andersen et al., 2012). These results suggested that $L$. acidophilus NCFM transports $\alpha$-galactosides into the cytoplasm via an $A B C$ system and then, they are hydrolyzed by the action of the $\mathrm{GH} 36$ a-galactosidase into galactose and sucrose or galactose and glucose.

\section{Metabolism of human milk oligosaccharides (HMOs)}

\section{Structural characteristics and functional properties of HMOs}

HMOs constitute a group of non-conjugated and structurally diverse carbohydrates that represent the third largest solid component of human milk after lactose and lipids (Kunz et al., 2000; Thurl et al., 2010). They consist of combinations of five monosaccharides: D-glucose, D-galactose, $\mathrm{N}$ acetylglucosamine (GIcNAc), L-fucose and sialic acid (Sia). The only form of Sia found in human milk is $\mathrm{N}$-acetylneuraminic acid (Neu5Ac), while oligosaccharides present in milk of other mammals may contain too $\mathrm{N}$-glycolylneuraminic acid (Neu5Gc) (Urashima et al., 2013). All HMOs contain a lactose unit ( $\beta$-D-galactopyranosyl- $(1 \rightarrow 4)$-Dglucopyranoside) at their reducing end, that can be further elongated by the addition of $\beta-1,3$-linked lacto- $N$-biose (LNB; $\beta$-D-galactopyranosyl-( $1 \rightarrow 3)-N$ acetyl-D-glucosamine; type-1 core) and/or $\beta 1-3 / 6$ linked $N$-acetyllactosamine (LacNAc; $\beta-D$ galactopyranosyl-( $1 \rightarrow 4)-N$-acetyl-D-glucosamine; type-2 chain). The basic core structures can be modified by L-Fuc with an $\alpha 1-2, \alpha 1-3$ or $\alpha 1-4$ linkage and/or Sia with an a2-3 or a2-6 linkage. HMOs can be simple trisaccharides as $2^{\prime} / 3^{\prime}$-fucosyllactose $\left(2^{\prime} /\right.$ $3^{\prime} \mathrm{FL}$ ) and $3^{\prime} / 66^{\prime}$-syalyllactose (6'SL) or complex oligosaccharides with several LNB and LacNAc repeat units (Bode, 2012). These disaccharides have also been found in free form in human milk (Balogh et al., 2015). Currently, over a 100 structurally distinct HMOs have been identified, including neutral (non-sialylated) and acidic (sialylated) compounds (Kobata, 2010). Most of the neutral HMOs are fucosylated, with concentrations ranging from 50 to $80 \%$, whereas sialylated $\mathrm{HMOs}$ ranged from 10 to $20 \%$. In contrast, only about $1 \%$ of the oligosaccharides are fucosylated in bovine milk (Bode, 2012). The overall concentration of HMOs varies during lactation, colostrum contains about 20-25 g/l HMOs and this amount diminishes to approximately $5-20 \mathrm{~g} / \mathrm{l}$ in mature milk (Bode, 2012; Thurl et al., 2010). In addition, the HMOs composition and quantity is variable among mothers, since their synthesis is correlated with the Secretor and Lewis blood group characteristics, which depend on the expression of FUT2 and FUT3 fucosyltransferases, respectively, within the mammary gland (Kunz et al., 2017; Thurl et al., 2010).

Human milk also contains highly glycosylated proteins, including mucins, that have attached oligosaccharide moieties with structures that resemble those of the free HMOs (Liu and Newburg, 2013). Both HMOs and the glycan moieties of the proteins are synthesized by the same glycosyltransferases. $\mathrm{N}$-glycans are linked to an asparagine residue through an GlcNAc, that is elongated by an additional GIcNAc residue through a $\beta-1,4$ linkage and three mannose residues. The GlcNAc residue linked to Asn can be modified via $\alpha-1,6-f u c o s y l a t i o n$ and the mannose residues with other monosaccharides, including L-fucose and Sia, and it becomes a complex structure (Nwosu et al., 2012). O-glycans usually contain an $N$ acetylgalactosamine (GalNAc) linked to a serine or threonine residue. In the type-1 sugar chain found in mucins, the GalNAc is extended with Gal, linked via a $\beta-1,3$ bond, forming the disaccharide galacto- $N$ biose (GNB; $\beta$-D-galactopyranosyl-( $1 \rightarrow 3)-N$-acetylD-galactosamine) (Figure 7). GNB is also present in glycosphingolipids and in bioactive sugar structures like the T-antigen disaccharide (Liu and Newburg, 2013; Moran et al., 2011).

In the last years, many studies have suggested that HMOs act as anti-adhesins against pathogens. HMOs are structurally similar to host receptors for 

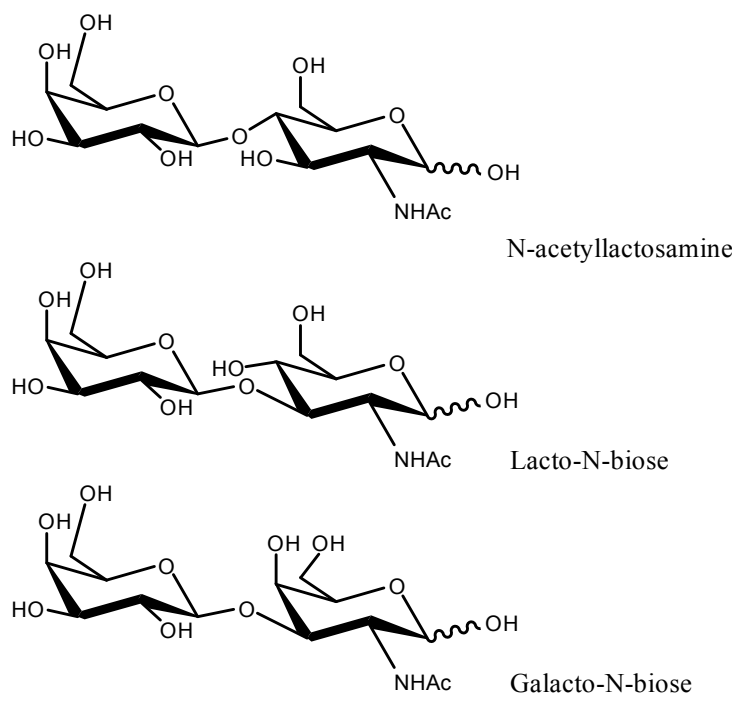

Figure 7. Chemical structures of $\mathrm{N}$-acetyllactosamine, lacto- $\mathrm{N}$-biose, and galacto- $\mathrm{N}$-biose.

pathogens since they are synthesized by the same glycosyltransferases that synthesize cell surface glycoproteins and glycolipids. As soluble receptor analogs, HMOs can act as decoys protecting infants against infections. Some HMOs inhibit the attachment of norovirus and bacterial pathogens such as Listeria monocytogenes and pathogenic $E$. coli strains (Newburg et al., 2005), Campylobacter jejuni (Ruiz-Palacios et al., 2003), Helicobacter pylori (Mysore et al., 1999) and parasites such as Entamoeba histolytica (Jantscher-Krenn et al., 2012), explaining the fact that breast-fed infants are at lower risk to acquire $E$. histolytica infections than formula-fed infants (Islam et al., 1988). Two disaccharides, $\alpha$-L-fucosyl-( $1 \rightarrow 3)-N$-acetyl-Dglucosamine (3FN) and $\alpha$-L-fucosyl-( $1 \rightarrow 6)-N$-acetylD-glucosamine (6FN) (Rodríguez-Díaz et al., 2013) that form part of the structure of many HMOs, either free or glycoconjugated to proteins, possess antiadhesive properties against the enteropahogenic $E$. coli (O86). 6FN was also able to block the binding of the enteropathogenic E. coli (O127a) to HT29 cells (Becerra et al., 2015a). Recently, it has been shown that HMOs function as antimicrobial and antibiofilm agents against Streptococcus agalactiae, an invasive pathogen in both children and adults (Ackerman et al., 2017; Lin et al., 2017). Interestingly, specific neutral HMOs directly inhibit the growth of this bacterium and a mutant impaired in a putative glycosyltransferase is resistant to those HMOs (Lin et al., 2017).
Metabolic pathways for HMOs in Lactobacillus Convincing evidence supports that HMOs favor the growth of beneficial bacteria present in the gastrointestinal tract of breastfed infants. HMOs were first identified as the prebiotic "bifidus factor" described for human milk. Bifidobacteria constitute a considerable proportion of the intestinal microbiota of infants (Gomez-Llorente et al., 2013), and they are highly adapted to use HMOs as a carbon source (Garrido et al., 2013). Genome analyses have revealed that strains of Bifidobacterium longum subsp. infantis, Bifidobacterium longum subsp. longum, Bifidobacterium breve and $B$. bifidum encode a battery of enzymes involved in HMOs catabolism (Kwak et al., 2016; LoCascio et al., 2010; Zúñiga et al., 2018). Unlike Bifidobacterium, species of the genera Lactobacillus, that are often isolated from breast-fed infant feces (Albesharat et al., 2011; Martín et al., 2007; Rubio et al., 2014), usually showed a limited capacity for HMOs utilization. The only exception is represented by members of the L. casei/paracasei/rhamnosus group, which contain several genes encoding enzymes involved in the hydrolysis of fucosyloligosaccharides (Rodríguez-Díaz et al., 2011) and in the metabolism of the type-1 (Bidart et al., 2014) and type-2 core structures from HMOs (Bidart et al., 2018) (Figure 8). Three $\alpha$-L-fucosidases (AlfA, AlfB and AlfC) encoded in the $L$. casei BL23 genome have been characterized and they were able to hydrolyze in vitro fucosylated HMOs (Rodríguez-Díaz et al., 2011). All three enzymes are possibly 
intracellularly located as they lack secretion signals, suggesting that $L$. casei must transport the fucosylated substrates into the cytoplasm before their hydrolysis. This notion was demonstrated for the disaccharide 3FN that is transported into the cells by the mannose-class PTS encoded by the genes alfEFG, without being phosphorylated: L-fucose is a 6-deoxy-galactose and therefore lacks a phosphorylatable hydroxyl group at the carbon in the sixth position. These genes are divergently oriented from the gene cluster alfBR, encoding the $\alpha$-L-fucosidase AlfB and the transcriptional repressor AlfR (Rodríguez-Díaz et al., 2012). AlfB digested the disaccharide within the cells into Lfucose and GIcNAc. The latter is metabolized by $L$. casei, whereas the L-fucose moiety is excreted to the medium (Figure 8) because, contrarily to $L$. rhamnosus GG (Becerra et al., 2015b), L. casei lacks L-fucose catabolic genes. Recently, the $\alpha-L-$ fucosidase AlfC, responsible for 6FN hydrolysis, has been shown to be involved in the use of the corefucosylated structures of $\mathrm{N}$-glycosylated proteins (Becerra et al., 2020). AlfC is encoded in a gene cluster (alf-2) that also contains the gene alfH, encoding a major facilitator superfamily (MFS) permease, and the divergently oriented asdA (aspartate 4-decarboxylase), alfR2 (transcriptional regulator), pepV (peptidase), asnA2 (glycosylasparaginase), and sugK (sugar kinase) genes (Becerra et al., 2020). The pathway involves the uptake of the glycoamino acid fucosyl- $\alpha-1,6-N-$ GlcNAc-Asn (6'FN-Asn) by the AlfH permease,

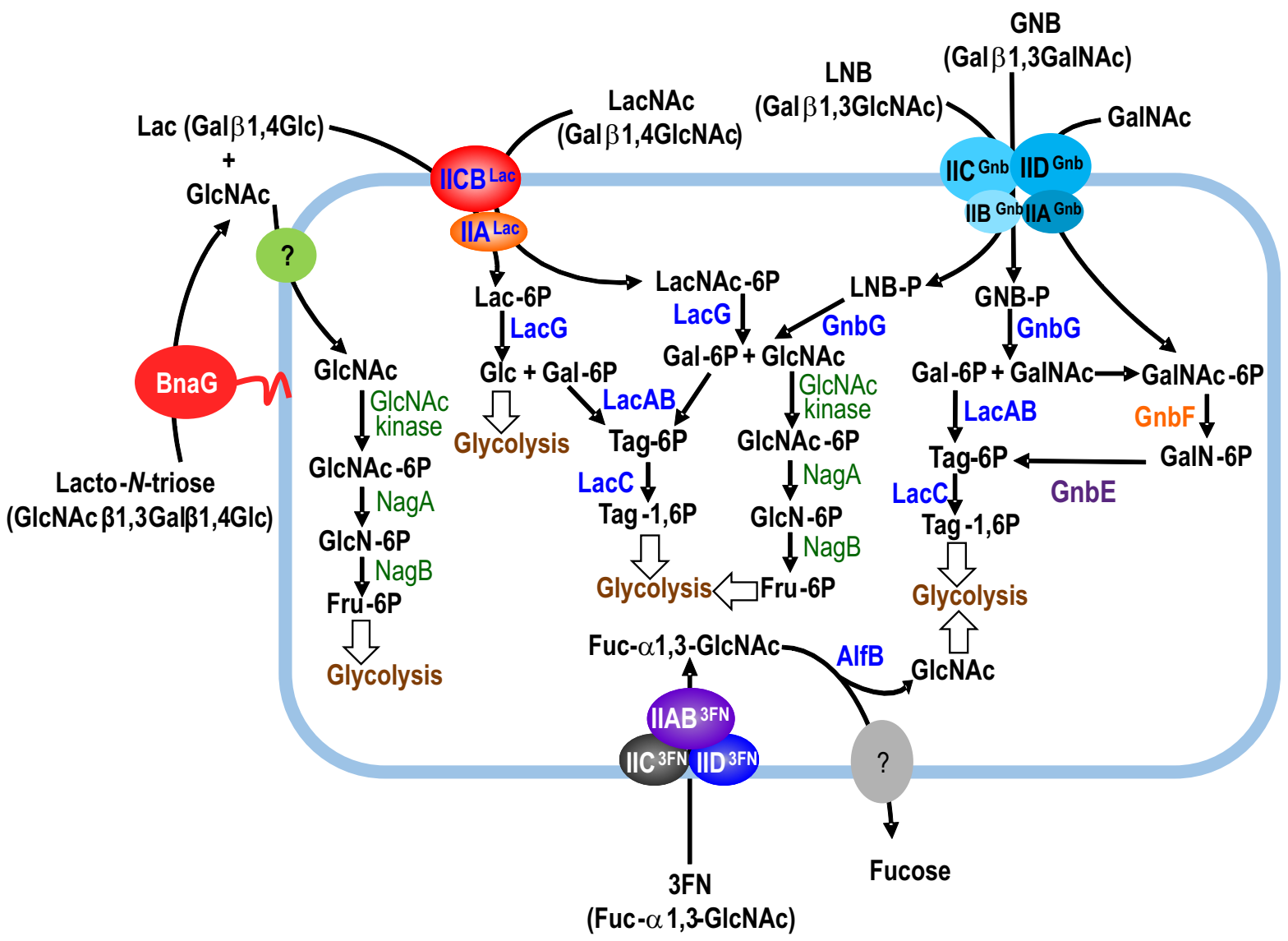

Figure 8. HMOs catabolic pathways identified in Lactobacillus casei. LNB, lacto-N-biose; GNB, galacto-N-biose; LacNAc, $N$-acetyllactosamine; Lac, lactose; GalNAc, N-acetylgalactosamine; GalN, galactosamine; Gal, galactose; Glc, glucose, GIcNAc; N-acetylglucosamine; GlcN, glucosamine; Tag, tagatose; 3FN, fucosyl-a1,3-N-acetylglucosamine; Fuc, fucose; IICB ${ }^{\text {Lac }}$ and IIA ${ }^{\text {Lac }}$, lactose-specific domains of the phosphoenolpyruvate: phosphotrans-

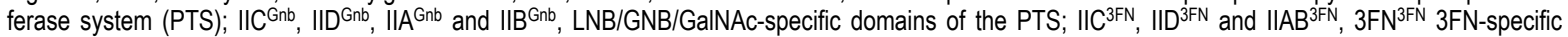
domains of the PTS; BnaG, beta- $N$-acetylglucosaminidase; LacG, phospho- $\beta$-galactosidase; GnbG, phospho- $\beta$-galactosidase; GnbF, $N$-acetylgalactosamine 6-phosphate deacetylase; GnbE, galactosamine 6-phosphate isomerase/deaminase; LacAB, galactose 6-phosphate isomerase; LacC, tagatose 6-phosphate kinase; NagA, $N$-acetylglucosamine 6-phosphate deacetylase; NagB, glucosamine 6-phosphate deaminase. 
removal of the $\alpha 1,6$-fucosyl residue by the $\alpha-L-$ fucosidase AlfC, and cleavage of the resulting GlcNAc-Asn to 1-amino-GlcNAc and Asp by the glycosylasparaginase AsnA2 (Figure 9). AlfH and AlfC are also involved in the transport and metabolism of other $\alpha 1,6$-fucosylated structures such as fucosyl- $\alpha-1,6-N, N$ '-diacetylchitobiose (N2F $N$-glycan), fucosyl- $\alpha-1,6-$ galactose and fucosyl$\alpha-1,6$-glucose (Becerra et al., 2020).

The release of L-fucose and Sia from the nonreducing ends is the first step to degrade the HMOs core structures. Bifidobacterium spp. and Bacteroides spp. generally are good consumers of fucosylated and sialylated HMOs as they usually possess fucosidase and sialidase activities. The last activity is not a common feature among lactobacilli, although L. delbrueckii ATCC7830 showed sialidase activity when cultured in the present of 6'sialyllactose (Yu et al., 2013). A number of lactobacilli contain genes enabling the use of Lfucose or Sia moieties released from HMOs. $L$. rhamnosus GG can utilize L-fucose since it contains an operon encoding a specific catabolic pathway similar to that of E. coli (Becerra et al., 2015b). L. sakei $23 \mathrm{~K}$ contains two gen clusters, nanTEAR and nanKMP involved in the catabolism of Neu5Ac (Anba-Mondoloni et al., 2013), and some strains of L. plantarum, L. salivarius (Almagro-Moreno and Boyd, 2009) and L. paracasei (Hammer et al., 2017) also contain genes for Sia metabolism. Extracellular sialidase and fucosidase activities have not been described in those species; therefore, the utilization of these carbohydrates as well as the glycan core structures by lactobacilli probably depends on their release from HMOs and mucin by other members of the intestinal microbiota. This is the case of $L$. casei, which has a complete machinery to metabolize HMOs and O-glycans core structures such as LNB, GNB (Bidart et al., 2014), LacNAc (Bidart et al., 2018) and lacto- $N$-triose II (LNTII; $\beta$-N-acetyl-Dglucosamine-( $1 \rightarrow 3)-\beta$-D-galactopyranosyl-( $1 \rightarrow 4)$-Dglucopyranoside) (Bidart et al., 2016) (Figure 8). LNB and GNB utilization relies on the gnb operon, which contains genes encoding a transcriptional repressor $(g n b R)$, a galactosamine 6-phosphate isomerizing deaminase (gnbE), a GalNAc 6phosphate deacetylase ( $g n b F)$, a phospho- $\beta$ galactosidase (gnbG) and four genes (gnbBCDA) encoding the EIIB, EIIC, EIID and EIIA components of a mannose-class PTS system (PTS ${ }^{\mathrm{Gnb}}$ ) (Bidart et al., 2014). LNB, GNB and also GalNAc are transported and phosphorylated by the PTSGnb and then, both disaccharides are hydrolyzed by the specific $\beta$-1,3-galactosidase GnbG (GH family 35 ) into galactose 6-phosphate and the corresponding $\mathrm{N}$-acetylhexosamines (GIcNAc and GalNAc). Galactose 6-phosphate is metabolized through the tagatose 6-phosphate pathway, whereas GlcNAc and GalNAc would be phosphorylated by as yet unknown kinases before entering different catabolic routes (Figure 8). GlcNAc 6-phosphate is converted by the NagA deacetylase to glucosamine 6phosphate, which enters the glycolysis pathway via conversion to fructose 6-phosphate by the NagB deaminase. GalNAc 6-phosphate would be deacetylated and deaminated to tagatose 6phosphate by the products of the genes $g n b F$ and gnbE. Therefore, all gnb genes would participate in GNB and GalNAc metabolism while LNB utilization by $L$. casei would not require $\mathrm{GnbE}$ and $\mathrm{GnbF}$ activities. It is worth noting that gnb genes are highly induced by GNB and GaINAc which relieve repression by $\mathrm{GnbR}$, whereas the presence of LNB barely induces the gnb operon (Bidart et al., 2014). According to this, the gnb operon would be primarily adapted to catabolize GNB and GalNAc. The coexistence of these sugars with LNB in environments as the gastrointestinal tract might account for the utilization of LNB by this pathway although this sugar would not induce the expression of gnb genes. The gnb gene cluster is conserved in the L. casei/paracasei/rhamnosus/zeae group, and it has been shown that both GNB and LNB are fermented by several strains of $L$. casei, $L$. rhamnosus and L. zeae species (Bidart et al., 2017). Strains belonging to $L$. gasseri and $L$. johnsonii species are also consumers of LNB and GNB, although they do not have a gnb operon (Bidart et al., 2017). Therefore, at least another catabolic system for those disaccharides remains to be discovered in lactobacilli.

Lactose metabolism in lactic acid bacteria has been widely studied due to the economic relevance of lactose fermentation in the dairy industry (Cavanagh et al., 2015; de Vos and Vaughan, 1994; Lapierre et al., 2002; Stefanovic et al., 2017). Lactose can be transported by lactose/galactose antiport permeases, proton symport permeases or through a PTS transporter (Alpert and Chassy, 1990; de Vos and Vaughan, 1994; Francl et al., 2012; Gosalbes et al., 1997; Leong-Morgenthaler et al., 1991). Recently, it has been shown that the lac operon from $L$. casei is also responsible of the utilization of LacNAc (Bidart et al., 2018). This carbohydrate is transported and phosphorylated by the PTSLac (Gosalbes et al., 2002; Gosalbes et al., 1997; Gosalbes et al., 1999), and then is hydrolyzed by the phospho- $\beta$-galactosidase LacG ( $\mathrm{GH}$ family 1 ) 
into galactose 6-phosphate and GlcNAc. In fact, the lac operon of $L$. casei showed higher induction levels in the presence of LacNAc than with lactose, suggesting that LacNAc may be the preferential substrate of this transporter. Indeed, this carbohydrate is present in the human gastrointestinal tract through all stages of life (Marionneau et al., 2001; Moran et al., 2011) whereas lactose would be only present during the lactating period since the introduction of dairy farming is a very recent event in the evolutionary history of humankind. Genome sequence analyses (http://www.ncbi.nlm.nih.gov/genomes) showed that many species belonging to the genus Lactobacillus contain genes encoding PTS transporters homologous to the PTS ${ }^{\mathrm{Lac}}$ from $L$. casei BL23, suggesting that lactose-specific PTS transporters are quite common among lactobacilli. Lactose is also the product resulting from the metabolism of LNTII by the action of the exoglycosidase $\beta-N$ - acetylglucosaminidase BnaG (GH family 20 ) from $L$. casei (Bidart et al., 2016). Unlike the other glycosidases active on HMOs characterized in this species, BnaG is a cell wall-anchored extracellular protein. This enzyme shows high specificity for $N$ acetylhexosaminyl- $\beta-1,3$-linked sugars as it releases GIcNAc not only from LNTII but also from $\beta-N-$ acetyl-D-glucosamine-(1 $\rightarrow 3)$-D-mannopyranoside, a disaccharide that forms part of glycoproteins (Garrido et al., 2012). As well, BnaG liberates GalNAc from $\beta-N$-acetyl-D-galactosamine-( $1 \rightarrow 3)$-Dgalactopyranoside, which forms part of globotetraose, a glycan moiety of human glycosphingolipids present at cell surfaces (Schnaar et al., 2009). The oligosaccharide part of these lipids have recently been described as substrates for lacto- $N$-biosidases isolated from $B$. longum subsp. longum, which, in contrast to BnaG, are endoglycosidases and release GNB (Gotoh et al., 2015). The possession of cell-wall attached

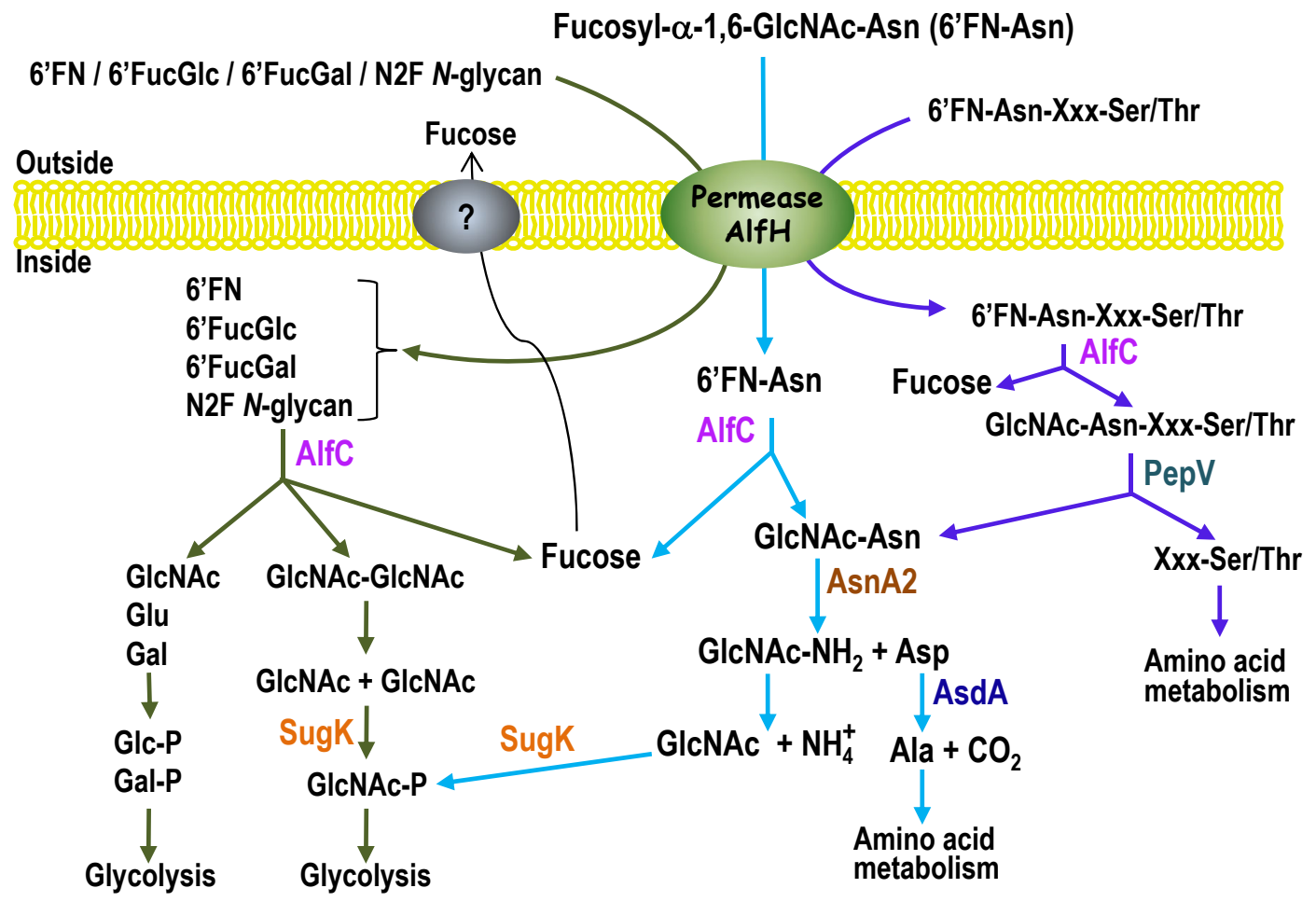

Figure 9. Schematic presentation of the transport and catabolic pathways for fucosyl-a-1,6- $N$-acetylglucosamine-asparagine (6'FN-Asn), fucosylated glycans and fucosylated $\mathrm{N}$-glycopeptides in Lactobacillus casei. AlfC, a-L-fucosidase AlfC; AsnA2, N(4)-( $\beta$ - $N$-acetylglucosaminyl)-L-asparaginase; AsdA, aspartate 4-decarboxylase; PepV, peptidase V; SugK, sugar kinase; GIcNAc, $N$-acetylglucosamine; Glc, glucose; Gal, galactose; 6'FN, fucosyl-a-1,6-Nacetylglucosamine; 6'FucGlc, fucosyl-a-1,6-glucose; 6'FucGal, fucosyl-a-1,6-galactose; N2F, N-glycan fucosyl-a-1,6-N,N'-diacetylchitobiose. 
glycosidases may provide a competitive advantage by allowing cleavage and consumption of complexlinked sugars. In addition, there is also evidence suggesting that these enzymes might also modulate the activity of host glycoproteins and pathogen-host receptor interactions through modification of the surface-exposed host glycans structures (Garbe and Collin, 2012; Garrido et al., 2012; Kobata, 2013).

The presence of $\alpha$-L-fucosidases and catabolic pathways for the utilization of LNB, GNB, LacNAc and LNTII in L. casei shows the capacity of this species for the exploitation of human milk and mucosa-associated glycans. This feature probably constitutes an adaptation of these bacteria to survive in the gastrointestinal tract of breastfed infants.

\section{Concluding remarks}

Lactobacilli play a major role in the production of many fermented foods and, in human and animal health as components of the microbial communities associated to different mucosal surfaces or as health-improving food supplements. These organisms rely on sugar utilization for growth so that knowing their sugar utilization pathways is a must to understand their role in microbial communities and their performance in food production. Due to their economic relevance, some species of lactobacilli have been extensively studied (e.g. specific strains of $L$. plantarum, $L$. casei or $L$. acidophilus) and the pathways of utilization of many monosaccharides and disaccharides have been elucidated. However, there are still great gaps in our knowledge of the utilization of complex glycans, especially host mucosal glycans, even in well characterized strains of lactobacilli. Also, information is partial or simply lacking for many other species that inhabit mucosal and food/feed niches. Genomic sequencing in lactobacilli has revealed an enormous variety of putative glycan transport systems and glycosyl hydrolases belonging to different $\mathrm{GH}$ families. However, the function of most of these transporters and enzymes remains to be elucidated. Furthermore, most studies have been carried out using pure cultures in laboratory conditions. However, utilization of complex glycans in food matrixes or microbial communities is possibly a key factor for growth and survival in these environments. In the natural niches where lactobacilli dwell, complex ecological relationships are found and cross-feeding is established between different microbial groups, where sequential and cooperative degradation of complex glycans probably takes place. Unraveling these associations will require the use of different "omic" technologies that include metagenomics, transcriptomics and metabolomics. This constitutes a future challenge in the study of carbohydrate metabolism in lactobacilli and its functional and ecological relevance.

\section{Acknowledgements}

This work was financed by funds of the Spanish Ministry of Science, Innovation and Universities (MICIU) and the EU FEDER program through the Projects AGL2017-84165-C2-1-R and RTI2018-098071-B-I00.

\section{References}

Ackerman, D.L., Craft, K.M., and Townsend, S.D. (2017). Infant food applications of complex carbohydrates: structure, synthesis, and function. Carbohydr. Res. 437, 16-27. http://dx.doi.org/ 10.1016/j.carres.2016.11.007.

Albenberg, L., Esipova, T.V., Judge, C.P., Bittinger, K., Chen, J., Laughlin, A., Grunberg, S., Baldassano, R.N., Lewis, J.D., Li, H., et al. (2014). Correlation between intraluminal oxygen gradient and radial partitioning of intestinal microbiota. Gastroenterology 147 , 1055-1063.e1058. https://doi.org/10.1053/j.gastro. 2014.07.020.

Albesharat, R., Ehrmann, M.A., Korakli, M., Yazaji, S., and Vogel, R.F. (2011). Phenotypic and genotypic analyses of lactic acid bacteria in local fermented food, breast milk and faeces of mothers and their babies. Syst. Appl. Microbiol. 34, 148-155. http://dx.doi.org/10.1016/j.syapm. 2010.12.001.

Almagro-Moreno, S., and Boyd, E.F. (2009). Insights into the evolution of sialic acid catabolism among bacteria. BMC Evol. Biol. 9, 118. http://dx.doi.org/ 10.1186/1471-2148-9-118.

Alpert, C.A., and Chassy, B.M. (1990). Molecular cloning and DNA sequence of lacE, the gene encoding the lactose-specific enzyme II of the phosphotransferase system of Lactobacillus casei. Evidence that a cysteine residue is essential for sugar phosphorylation. J. Biol. Chem. 265, 22561-22568.

Ananieva, M., Tzenova, M., lliev, I., and Ivanova, I. (2014). Gene expression of enzymes involved in utilization of xylooligosaccharides by Lactobacillus strains. Biotechnol. Biotechnol. Equip. 28, 941-948. ht t p://dx.doi.org/ 10.1080/13102818.2014.948257.

Anba-Mondoloni, J., Chaillou, S., Zagorec, M., and Champomier-Verges, M.C. (2013). Catabolism of $\mathrm{N}$-acetylneuraminic acid, a fitness function of the 
food-borne lactic acid bacterium Lactobacillus sakei, involves two newly characterized proteins. Appl. Environ. Microbiol. 79, 2012-2018. http:// dx.doi.org/10.1128/AEM.03301-12.

Andersen, J.M., Barrangou, R., Abou Hachem, M., Lahtinen, S., Goh, Y.J., Svensson, B., and Klaenhammer, T.R. (2011). Transcriptional and functional analysis of galactooligosaccharide uptake by lacS in Lactobacillus acidophilus. Proc. Natl. Acad. Sci. USA 108, 17785-17790. http:// dx.doi.org/10.1073/pnas.1114152108.

Andersen, J.M., Barrangou, R., Hachem, M.A., Lahtinen, S.J., Goh, Y.J., Svensson, B., and Klaenhammer, T.R. (2012). Transcriptional analysis of prebiotic uptake and catabolism by Lactobacillus acidophilus NCFM. PLoS ONE 7, e44409. http://dx.doi.org/10.1371/journal.pone. 0044409.

Anwar, M.A., Kralj, S., van der Maarel, M.J.E.C., and Dijkhuizen, L. (2008). The probiotic Lactobacillus johnsonii NCC 533 produces highmolecular-mass inulin from sucrose by using an inulosucrase enzyme. Appl. Environ. Microbiol. 74, 3426-3433. http://dx.doi.org/10.1128/aem. 00377-08.

Balogh, R., Jankovics, P., and Beni, S. (2015). Qualitative and quantitative analysis of $\mathrm{N}$ acetyllactosamine and lacto- $\mathrm{N}$-biose, the two major building blocks of human milk oligosaccharides in human milk samples by highperformance liquid chromatography-tandem mass spectrometry using a porous graphitic carbon column. J. Chromatogr. A 1422, 140-146. http:// dx.doi.org/10.1016/j.chroma.2015.10.006.

Balolong, M.P., Chae, J.P., and Kang, D.K. (2016). Expression and characterisation of neopullulanase from Lactobacillus mucosae. Biotechnol. Lett. 38, 1753-1760. http://dx.doi.org/10.1007/ s10529-016-2152-x.

Barrangou, R., Altermann, E., Hutkins, R., Cano, R., and Klaenhammer, T.R. (2003). Functional and comparative genomic analyses of an operon involved in fructooligosaccharide utilization by Lactobacillus acidophilus. PNAS 100, 8957-8962. http://dx.doi.org/10.1073/pnas.1332765100.

Barrangou, R., Azcarate-Peril, M.A., Duong, T., Conners, S.B., Kelly, R.M., and Klaenhammer, T.R. (2006). Global analysis of carbohydrate utilization by Lactobacillus acidophilus using cDNA microarrays. PNAS 103, 3816-3821. http:// dx.doi.org/10.1073/pnas.0511287103.

Becerra, J.E., Coll-Marques, J.M., Rodriguez-Diaz, J., Monedero, V., and Yebra, M.J. (2015a). Preparative scale purification of fucosyl-Nacetylglucosamine disaccharides and their evaluation as potential prebiotics and antiadhesins. Appl. Microbiol. Biotechnol. 99, 7165-7176. http://dx.doi.org/10.1007/ s00253-015-6666-2.

Becerra, J.E., Rodríguez-Díaz, J., Gozalbo-Rovira, R., Palomino-Schätzlein, M., Zúñiga, M., Monedero, V., and Yebra, M.J. (2020). Unique microbial catabolic pathway for the human core $\mathrm{N}$ glycan constituent fucosyl- $\alpha-1,6-N$-acetylglucosamine-asparagine. mBio 11, e02804-02819. https://doi.org/10.1128/mBio.02804-19.

Becerra, J.E., Yebra, M.J., and Monedero, V. (2015b). An L-Fucose operon in the probiotic Lactobacillus rhamnosus GG is involved in adaptation to gastrointestinal conditions. Appl. Environ. Microbiol. 81, 3880-3888. http:// dx.doi.org/10.1128/AEM.00260-15.

Bello, F.D., Walter, J., Hertel, C., and Hammes, W.P. (2001). In vitro study of prebiotic properties of levan-type exopolysaccharides from lactobacilli and non-digestible carbohydrates using denaturing gradient gel electrophoresis. Syst. Appl. Microbiol. 24, 232-237. http://dx.doi.org/ 10.1078/0723-2020-00033.

Bidart, G.N., Rodriguez-Diaz, J., Monedero, V., and Yebra, M.J. (2014). A unique gene cluster for the utilization of the mucosal and human milkassociated glycans galacto-N-biose and lacto-Nbiose in Lactobacillus casei. Mol. Microbiol. 93, 521-538. http://dx.doi.org/10.1111/mmi.12678.

Bidart, G.N., Rodriguez-Diaz, J., PalominoSchatzlein, M., Monedero, V., and Yebra, M.J. (2017). Human milk and mucosal lacto- and galacto-N-biose synthesis by transgalactosylation and their prebiotic potential in Lactobacillus species. Appl. Microbiol. Biotechnol. 101, 205-215. http://dx.doi.org/10.1007/ s00253-016-7882-0.

Bidart, G.N., Rodríguez-Díaz, J., Pérez-Martínez, G., and Yebra, M.J. (2018). The lactose operon from Lactobacillus casei is involved in the transport and metabolism of the human milk oligosaccharide core-2 N-acetyllactosamine. Sci. Rep. 8, 7152. https://doi.org/10.1038/ s41598-018-25660-w.

Bidart, G.N., Rodriguez-Diaz, J., and Yebra, M.J. (2016). The extracellular wall-bound beta-Nacetylglucosaminidase from Lactobacillus casei is involved in the metabolism of the human milk oligosaccharide lacto-N-triose. Appl. Environ. Microbiol. 82, 570-577. http://dx.doi.org/10.1128/ AEM.02888-15.

Blander, J.M., Longman, R.S., Iliev, I.D., Sonnenberg, G.F., and Artis, D. (2017). Regulation of inflammation by microbiota 
interactions with the host. Nat. Immunol. 18, 851-860. http://dx.doi.org/10.1038/ni.3780.

Bode, L. (2012). Human milk oligosaccharides: every baby needs a sugar mama. Glycobiology 22, 1147-1162. http://dx.doi.org/10.1093/glycob/ cws074.

Cantarel, B.L., Lombard, V., and Henrissat, B. (2012). Complex carbohydrate utilization by the healthy human microbiome. PLoS ONE 7, e28742. http://dx.doi.org/10.1371/journal.pone. 0028742.

Cardelle-Cobas, A., Fernández, M., Salazar, N., Martínez-Villaluenga, C., Villamiel, M., RuasMadiedo, P., and de los Reyes-Gavilán, C.G. (2009). Bifidogenic effect and stimulation of short chain fatty acid production in human faecal slurry cultures by oligosaccharides derived from lactose and lactulose. J. Dairy Res. 76, 317-325. http:// dx.doi.org/10.1017/S0022029909004063.

Carrera-Silva, E.A., Silvestroni, A., LeBlanc, J.G., Piard, J.C., Savoy de Giori, G., and Sesma, F. (2006). A thermostable alpha-galactosidase from Lactobacillus fermentum CRL722: genetic characterization and main properties. Curr. Microbiol. 53, 374-378. http://dx.doi.org/10.1007/ s00284-005-0442-y.

Cavanagh, D., Fitzgerald, G.F., and McAuliffe, O. (2015). From field to fermentation: the origins of Lactococcus lactis and its domestication to the dairy environment. Food Microbiol. 47, 45-61. http://dx.doi.org/10.1016/j.fm.2014.11.001.

Chaillou, S., Lokman, B.C., Leer, R.J., Posthuma, C., Postma, P.W., and Pouwels, P.H. (1998). Cloning, sequence analysis, and characterization of the genes involved in isoprimeverose metabolism in Lactobacillus pentosus. J. Bacteriol. 180, 2312-2320.

Chen, C., Zhao, G., Chen, W., and Guo, B. (2015). Metabolism of fructooligosaccharides in Lactobacillus plantarum ST-III via differential gene transcription and alteration of cell membrane fluidity. Appl. Environ. Microbiol. 81, 7697-7707. http://dx.doi.org/10.1128/aem.02426-15.

Chen, C., Zhou, F., Ren, J., Ai, L., Dong, Y., Wu, Z., Liu, Z., Chen, W., and Guo, B. (2014). Cloning, expression and functional validation of a $\beta$ fructofuranosidase from Lactobacillus plantarum. Process Biochem. 49, 758-767. http://dx.doi.org/ 10.1016/j.procbio.2014.02.013.

Chen, X.Y., Levy, C., and Ganzle, M.G. (2016). Structure-function relationships of bacterial and enzymatically produced reuterans and dextran in sourdough bread baking application. Int. J. Food Microbiol. 239, 95-102. http://dx.doi.org/10.1016/ j.ijfoodmicro.2016.06.010.
Cheng, K.-C., Demirci, A., and Catchmark, J.M. (2011). Pullulan: biosynthesis, production, and applications. Appl. Microbiol. Biotechnol. 92, 29. http://dx.doi.org/10.1007/s00253-011-3477-y.

Childs, C.E., Roytio, H., Alhoniemi, E., Fekete, A.A., Forssten, S.D., Hudjec, N., Lim, Y.N., Steger, C.J., Yaqoob, P., Tuohy, K.M., et al. (2014). Xylooligosaccharides alone or in synbiotic combination with Bifidobacterium animalis subsp. lactis induce bifidogenesis and modulate markers of immune function in healthy adults: a double-blind, placebocontrolled, randomised, factorial cross-over study. Br. J. Nutr. 111, 1945-1956. http://dx.doi.org/ 10.1017/S0007114513004261.

Cho, I., and Blaser, M.J. (2012). The human microbiome: at the interface of health and disease. Nat. Rev. Genet. 13, 260-270. http:// dx.doi.org/10.1038/nrg3182.

Claesson, M.J., Jeffery, I.B., Conde, S., Power, S.E., O'Connor, E.M., Cusack, S., Harris, H.M.B., Coakley, M., Lakshminarayanan, B., O'Sullivan, O., et al. (2012). Gut microbiota composition correlates with diet and health in the elderly. Nature 488, 178-184. http://dx.doi.org/10.1038/ nature11319.

Collado, M.C., Calabuig, M., and Sanz, Y. (2007). Differences between the fecal microbiota of coeliac infants and healthy controls. Curr. Issues Intest. Microbiol. 8, 9-14.

Coulier, L., Timmermans, J., Bas, R., Van Den Dool, R., Haaksman, I., Klarenbeek, B., Slaghek, T., and Van Dongen, W. (2009). In-depth characterization of prebiotic galactooligosaccharides by a combination of analytical techniques. J. Agric. Food Chem. 57, 8488-8495. http://dx.doi.org/10.1021/jf902549e.

David, L.A., Maurice, C.F., Carmody, R.N., Gootenberg, D.B., Button, J.E., Wolfe, B.E., Ling, A.V., Devlin, A.S., Varma, Y., Fischbach, M.A., et al. (2014). Diet rapidly and reproducibly alters the human gut microbiome. Nature 505, 559-563. http://dx.doi.org/10.1038/nature12820.

de Vos, W.M., and Vaughan, E.E. (1994). Genetics of lactose utilization in lactic acid bacteria. FEMS Microbiol. Rev. 15, 217-237.

Delgado, S., Flórez, A.B., Guadamuro, L., and Mayo, B. (2017). Genetic and biochemical characterization of an oligo-alpha-1,6-glucosidase from Lactobacillus plantarum. Int. J. Food Microbiol. 246, 32-39. http://dx.doi.org/10.1016/ j.ijfoodmicro.2017.01.021.

Dong, J.L., Yu, X., Dong, L.E., and Shen, R.L. (2017). In vitro fermentation of oat beta-glucan and hydrolysates by fecal microbiota and selected 
probiotic strains. J. Sci. Food Agric. 97, 4198-4203. http://dx.doi.org/10.1002/jsfa.8292.

Eckburg, P.B., Bik, E.M., Bernstein, C.N., Purdom, E., Dethlefsen, L., Sargent, M., Gill, S.R., Nelson, K.E., and Relman, D.A. (2005). Diversity of the human intestinal microbial flora. Science 308, 1635-1638. http://dx.doi.org/10.1126/science. 1110591.

Egloff, M.P., Uppenberg, J., Haalck, L., and van Tilbeurgh, H. (2001). Crystal structure of maltose phosphorylase from Lactobacillus brevis: unexpected evolutionary relationship with glucoamylases. Structure 9, 689-697. https:// doi.org/10.1016/S0969-2126(01)00626-8.

Ehrmann, M.A., and Vogel, R.F. (1998). Maltose metabolism of Lactobacillus sanfranciscensis: cloning and heterologous expression of the key enzymes, maltose phosphorylase and phosphoglucomutase. FEMS Microbiol. Lett. 169, 81-86. http://dx.doi.org/ 10.1111/j.1574-6968.1998.tb13302.x.

Ejby, M., Fredslund, F., Vujicic-Zagar, A., Svensson, B., Slotboom, D.J., and Abou Hachem, M. (2013). Structural basis for arabinoxylo-oligosaccharide capture by the probiotic Bifidobacterium animalis subsp. lactis BI-04. Mol Microbiol 90, 1100-1112. 10.1111/mmi.12419.

Endo, A., Nakamura, S., Konishi, K., Nakagawa, J., and Tochio, T. (2016). Variations in prebiotic oligosaccharide fermentation by intestinal lactic acid bacteria. Int. J. Food Sci. Nutr. 67, 125-132. http://dx.doi.org/10.3109/09637486.2016.1147019.

Ezenwa, V.O., Gerardo, N.M., Inouye, D.W., Medina, M., and Xavier, J.B. (2012). Animal behavior and the microbiome. Science 338, 198-199. http://dx.doi.org/10.1126/science. 1227412.

Francke, C., Kerkhoven, R., Wels, M., and Siezen, R.J. (2008). A generic approach to identify transcription factor-specific operator motifs; inferences for Lacl-family mediated regulation in Lactobacillus plantarum WCFS1. BMC Genom. 9, 145. http://dx.doi.org/10.1186/1471-2164-9-145.

Francl, A.L., Hoeflinger, J.L., and Miller, M.J. (2012). Identification of lactose phosphotransferase systems in Lactobacillus gasseri ATCC 33323 required for lactose utilization. Microbiology 158 , 944-952. http://dx.doi.org/10.1099/mic. 0.052928-0.

Fraunhofer, M.E., Geissler, A.J., Wefers, D., Bunzel, M., Jakob, F., and Vogel, R.F. (2017). Characterization of $ß$-glucan formation by Lactobacillus brevis TMW 1.2112 isolated from slimy spoiled beer. Int. J. Biol. Macromol. 107, 874-881 http://dx.doi.org/10.1016/j.ijbiomac. 2017.09.063.
Fuchs, A. (1991). Current and potential food and non-food applications of fructans. Biochem. Soc. Trans. 19, 555-560. http://dx.doi.org/10.1042/ bst0190555.

Ganzle, M.G., and Follador, R. (2012). Metabolism of oligosaccharides and starch in lactobacilli: a review. Front. Microbiol. 3, 340. http://dx.doi.org/ 10.3389/fmicb.2012.00340.

Garai-Ibabe, G., Dueñas, M.T., Irastorza, A., SierraFilardi, E., Werning, M.L., López, P., Corbi, A.L., and Fernández de Palencia, P. (2010). Naturally occurring 2-substituted (1,3)-beta-D-glucan producing Lactobacillus suebicus and Pediococcus parvulus strains with potential utility in the production of functional foods. Bioresour. Technol. 101, 9254-9263. http://dx.doi.org/ 10.1016/j.biortech.2010.07.050.

Garbe, J., and Collin, M. (2012). Bacterial hydrolysis of host glycoproteins - powerful protein modification and efficient nutrient acquisition. J. Innate Immun. 4, 121-131. http://dx.doi.org/ 10.1159/000334775.

Garrido, D., Dallas, D.C., and Mills, D.A. (2013). Consumption of human milk glycoconjugates by infant-associated bifidobacteria: mechanisms and implications. Microbiology 159, 649-664. http:// dx.doi.org/10.1099/mic.0.064113-0.

Garrido, D., Nwosu, C., Ruiz-Moyano, S., Aldredge, D., German, J.B., Lebrilla, C.B., and Mills, D.A. (2012). Endo-beta-N-acetylglucosaminidases from infant gut-associated bifidobacteria release complex N-glycans from human milk glycoproteins. Mol. Cell. Proteomics 11, 775-785. http://dx.doi.org/10.1074/mcp.M112.018119.

Gibson, G.R., and Roberfroid, M.B. (1995). Dietary modulation of the human colonic microbiota: introducing the concept of prebiotics. J. Nutr. 125, 1401-1412.

Goh, Y.J., and Klaenhammer, T.R. (2013). A functional glycogen biosynthesis pathway in Lactobacillus acidophilus: expression and analysis of the $g / g$ operon. Mol. Microbiol. 89, 1187-1200. http://dx.doi.org/10.1111/mmi.12338.

Goh, Y.J., and Klaenhammer, T.R. (2014). Insights into glycogen metabolism in Lactobacillus acidophilus: impact on carbohydrate metabolism, stress tolerance and gut retention. Microb. Cell Fact. 13, 94. http://dx.doi.org/10.1186/ s12934-014-0094-3.

Goh, Y.J., and Klaenhammer, T.R. (2015). Genetic mechanisms of prebiotic oligosaccharide metabolism in probiotic microbes. Annu. Rev. Food Sci. Technol. 6, 137-156. http://dx.doi.org/ 10.1146/annurev-food-022814-015706. 
Goh, Y.J., Lee, J.-H., and Hutkins, R.W. (2007). Functional analysis of the fructooligosaccharide utilization operon in Lactobacillus paracasei 1195. Appl. Environ. Microbiol. 73, 5716-5724. http:// dx.doi.org/10.1128/aem.00805-07.

Goh, Y.J., Zhang, C., Benson, A.K., Schlegel, V., Lee, J.-H., and Hutkins, R.W. (2006). Identification of a putative operon involved in fructooligosaccharide utilization by Lactobacillus paracasei. Appl. Environ. Microbiol. 72, 7518-7530. http://dx.doi.org/10.1128/aem. 00877-06.

Gomez-Llorente, C., Plaza-Diaz, J., Aguilera, M., Munoz-Quezada, S., Bermudez-Brito, M., PesoEcharri, P., Martinez-Silla, R., Vasallo-Morillas, M.I., Campana-Martin, L., Vives-Pinera, I., et al. (2013). Three main factors define changes in fecal microbiota associated with feeding modality in infants. J. Pediatr. Gastroenterol. Nutr. 57, 461-466. http://dx.doi.org/10.1097/MPG. 0b013e31829d519a.

Gosalbes, M.J., Esteban, C.D., and Pérez-Martínez, G. (2002). In vivo effect of mutations in the antiterminator LacT in Lactobacillus casei. Microbiology 148, 695-702. http://dx.doi.org/ 10.1099/00221287-148-3-695.

Gosalbes, M.J., Monedero, V., Alpert, C.A., and Perez-Martinez, G. (1997). Establishing a model to study the regulation of the lactose operon in Lactobacillus casei. FEMS Microbiol. Lett. 148, 83-89. https://doi.org/10.1016/ S0378-1097(97)00017-7.

Gosalbes, M.J., Monedero, V., and Perez-Martinez, G. (1999). Elements involved in catabolite repression and substrate induction of the lactose operon in Lactobacillus casei. J. Bacteriol. 181, 3928-3934.

Gotoh, A., Katoh, T., Sugiyama, Y., Kurihara, S., Honda, Y., Sakurama, H., Kambe, T., Ashida, H., Kitaoka, M., Yamamoto, K., et al. (2015). Novel substrate specificities of two lacto-N-biosidases towards beta-linked galacto-N-biose-containing oligosaccharides of globo $\mathrm{H}, \mathrm{Gb5}$, and GA1. Carbohydr. Res. 408, 18-24. http://dx.doi.org/ 10.1016/j.carres.2015.03.005.

Gu, S., Chen, D., Zhang, J.-N., Lv, X., Wang, K., Duan, L.-P., Nie, Y., and Wu, X.-L. (2013). Bacterial community mapping of the mouse gastrointestinal tract. PLoS ONE 8, e74957. http:// dx.doi.org/10.1371/journal.pone.0074957.

Hammer, A.J., Walters, A., Carroll, C., Newell, P.D., and Chaston, J.M. (2017). Draft genome sequence of Lactobacillus paracasei DmW181, a bacterium isolated from wild Drosophila. Genome
Announc. 5, e00545-00517. http://dx.doi.org/ 10.1128/genomeA.00545-17.

Heuberger, E.H., Smits, E., and Poolman, B. (2001). Xyloside transport by XyIP, a member of the galactoside-pentoside-hexuronide family. J. Biol. Chem. 276, 34465-34472. http://dx.doi/org/ 10.1074/jbc.M105460200.

Hidaka, H., Eida, T., Takizawa, T., Tokunaga, T., and Tashiro, Y. (1986). Effects of fructooligosaccharides on intestinal flora and human health. Bifidobact. Microfl. 5, 37-50.

Homburg, C., Bommer, M., Wuttge, S., Hobe, C., Beck, S., Dobbek, H., Deutscher, J., Licht, A., and Schneider, E. (2017). Inducer exclusion in Firmicutes: insights into the regulation of a carbohydrate ATP binding cassette transporter from Lactobacillus casei BL23 by the signal transducing protein P-Ser46-HPr. Mol. Microbiol. 105, 25-45. http://dx.doi.org/10.1111/mmi.13680.

Hooper, L.V., Midtvedt, T., and Gordon, J.I. (2002). How host-microbial interactions shape the nutrient environment of the mammalian intestine. Annu. Rev. Nutr. 22, 283-307. http://dx.doi.org/10.1146/ annurev.nutr.22.011602.092259.

$\mathrm{Hu}$, Y., Ketabi, A., Buchko, A., and Ganzle, M.G. (2013). Metabolism of isomalto-oligosaccharides by Lactobacillus reuteri and bifidobacteria. Lett. Appl. Microbiol. 57, 108-114. http://dx.doi.org/ 10.1111/lam.12076.

Humblot, C., Turpin, W., Chevalier, F., Picq, C., Rochette, I., and Guyot, J.P. (2014). Determination of expression and activity of genes involved in starch metabolism in Lactobacillus plantarum A6 during fermentation of a cerealbased gruel. Int. J. Food Microbiol. 185, 103-111. http://dx.doi.org/10.1016/j.ijfoodmicro. 2014.05.016.

Hutkins, R.W., Krumbeck, J.A., Bindels, L.B., Cani, P.D., Fahey, G., Goh, Y.J., Hamaker, B., Martens, E.C., Mills, D.A., Rastal, R.A., et al. (2016). Prebiotics: why definitions matter. Curr. Opin. Biotechnol. 37, 1-7. http://dx.doi.org/10.1016/ j.copbio.2015.09.001.

Huwel, S., Haalck, L., Conrath, N., and Spener, F. (1997). Maltose phosphorylase from Lactobacillus brevis: purification, characterization, and application in a biosensor for ortho-phosphate. Enzyme Microb. Technol. 21, 413-420. https:// doi.org/10.1016/S0141-0229(97)00014-8.

Islam, A., Stoll, B.J., Ljungstrom, I., Biswas, J., Nazrul, H., and Huldt, G. (1988). The prevalence of Entamoeba histolytica in lactating women and in their infants in Bangladesh. Trans. R. Soc. Trop. Med. Hyg. 82, 99-103. https://doi.org/ 10.1016/0035-9203(88)90276-3. 
Jantscher-Krenn, E., Lauwaet, T., Bliss, L.A., Reed, S.L., Gillin, F.D., and Bode, L. (2012). Human milk oligosaccharides reduce Entamoeba histolytica attachment and cytotoxicity in vitro. Br. J. Nutr. 108, 1839-1846. http://dx.doi.org/10.1017/ S0007114511007392.

Jones, L., Seymour, G.B., and Knox, J.P. (1997). Localization of pectic galactan in tomato cell walls using a monoclonal antibody specific to (1[->]4)[beta]-D-galactan. Plant Physiol. 113, 1405-1412. https://doi.org/10.1104/pp.113.4.1405.

Kaplan, H., and Hutkins, R.W. (2000). Fermentation of fructooligosaccharides by lactic acid bacteria and bifidobacteria. Appl. Environ. Microbiol. 66, 2682-2684. http://dx.doi.org/10.1128/aem. 66.6.2682-2684.2000.

Ketabi, A., Dieleman, L.A., and Ganzle, M.G. (2011). Influence of isomalto-oligosaccharides on intestinal microbiota in rats. J. Appl. Microbiol. 110, 1297-1306. http://dx.doi.org/10.1111/j. 1365-2672.2011.04984.x.

Kim, H.B., and Isaacson, R.E. (2015). The pig gut microbial diversity: understanding the pig gut microbial ecology through the next generation high throughput sequencing. Vet. Microbiol. 177, 242-251. http://dx.doi.org/10.1016/j.vetmic. 2015.03.014.

Kim, J.H., Sunako, M., Ono, H., Murooka, Y., Fukusaki, E., and Yamashita, M. (2008). Characterization of gene encoding amylopullulanase from plant-originated lactic acid bacterium, Lactobacillus plantarum L137. J. Biosci. Bioeng. 106, 449-459. http://dx.doi.org/ 10.1263/jbb.106.449.

Kleeberger, A., and Kühbauch, W. (1976). Über den Abbau von Grasfruktosanen durch Laktobazillen aus Silage. Zentralblatt für Bakteriologie, Parasitenkunde, Infektionskrankheiten und Hygiene. Zweite Naturwissenschaftliche Abteilung: Allgemeine, Landwirtschaftliche und Technische Mikrobiologie 131, 398-404. http:// dx.doi.org/10.1016/S0044-4057(76)80018-4.

Kobata, A. (2010). Structures and application of oligosaccharides in human milk. Proc. Jpn. Acad. Ser. B Phys. Biol. Sci. 86, 731-747. https://doi.org/ 10.2183/pjab.86.731.

Kobata, A. (2013). Exo- and endoglycosidases revisited. Proc. Jpn. Acad. Ser. B Phys. Biol. Sci. 89, 97-117. https://doi.org/10.2183/pjab.89.97.

Kohl, K.D., Amaya, J., Passement, C.A., Dearing, M.D., and McCue, M.D. (2014). Unique and shared responses of the gut microbiota to prolonged fasting: a comparative study across five classes of vertebrate hosts. FEMS Microbiol.
Ecol. 90, 883-894. http://dx.doi.org/ 10.1111/1574-6941.12442.

Kunz, C., Meyer, C., Collado, M.C., Geiger, L., García-Mantrana, I., Bertua-Ríos, B., MartínezCosta, C., Borsch, C., and Rudloff, S. (2017). Influence of gestational age, secretor, and Lewis blood group status on the oligosaccharide content of human milk. J. Pediatr. Gastroenterol. Nutr. 64, 789-798. http://dx.doi.org/10.1097/MPG. 0000000000001402.

Kunz, C., Rudloff, S., Baier, W., Klein, N., and Strobel, S. (2000). Oligosaccharides in human milk: structural, functional, and metabolic aspects. Annu. Rev. Nutr. 20, 699-722. http://dx.doi.org/ 10.1146/annurev.nutr.20.1.699.

Kuzuwa, S., Yokoi, K.-j., Kondo, M., Kimoto, H., Yamakawa, A., Taketo, A., and Kodaira, K.-I. (2012). Properties of the inulinase gene levH1 of Lactobacillus casei IAM 1045; cloning, mutational and biochemical characterization. Gene 495, 154-162. https://doi.org/10.1016/j.gene. 2011.12.004.

Kwak, M.J., Kwon, S.K., Yoon, J.K., Song, J.Y., Seo, J.G., Chung, M.J., and Kim, J.F. (2016). Evolutionary architecture of the infant-adapted group of Bifidobacterium species associated with the probiotic function. Syst. Appl. Microbiol. 39, 429-439. http://dx.doi.org/10.1016/j.syapm. 2016.07.004.

Lapierre, L., Mollet, B., and Germond, J.E. (2002). Regulation and adaptive evolution of lactose operon expression in Lactobacillus delbrueckii. J. Bacteriol. 184, 928-935. http://dx.doi.org/10.1128/ jb.184.4.928-935.2002.

LeBlanc, J.G., Garro, M.S., and Savoy de Giori, G. (2004). Effect of pH on Lactobacillus fermentum growth, raffinose removal, alpha-galactosidase activity and fermentation products. Appl. Microbiol. Biotechnol. 65, 119-123. http:// dx.doi.org/10.1007/s00253-003-1532-z.

Leemhuis, H., Dobruchowska, J.M., Ebbelaar, M., Faber, F., Buwalda, P.L., van der Maarel, M.J., Kamerling, J.P., and Dijkhuizen, L. (2014). Isomalto/malto-polysaccharide, a novel soluble dietary fiber made via enzymatic conversion of starch. J. Agric. Food Chem. 62, 12034-12044. http://dx.doi.org/10.1021/jf503970a.

Leong-Morgenthaler, P., Zwahlen, M.C., and Hottinger, H. (1991). Lactose metabolism in Lactobacillus bulgaricus: analysis of the primary structure and expression of the genes involved. J. Bacteriol. 173, 1951-1957. http://dx.doi.org/ 10.1128/jb.173.6.1951-1957.1991.

Ley, R.E., Turnbaugh, P.J., Klein, S., and Gordon, J.I. (2006). Microbial ecology: human gut 
microbes associated with obesity. Nature 444, 1022-1023. https://doi.org/doi:10.1038/4441022a.

Li, M., Wang, B., Zhang, M., Rantalainen, M., Wang, S., Zhou, H., Zhang, Y., Shen, J., Pang, X., Zhang, M., et al. (2008). Symbiotic gut microbes modulate human metabolic phenotypes. PNAS 105, 2117-2122. http://dx.doi.org/10.1073/pnas. 0712038105.

Lin, A.E., Autran, C.A., Szyszka, A., Escajadillo, T., Huang, M., Godula, K., Prudden, A.R., Boons, G.J., Lewis, A.L., Doran, K.S., et al. (2017). Human milk oligosaccharides inhibit growth of group B Streptococcus. J. Biol. Chem. 292, 11243-11249. http://dx.doi.org/10.1074/ jbc.M117.789974.

Lin, S.H., Chou, L.M., Chien, Y.W., Chang, J.S., and Lin, C.I. (2016). Prebiotic effects of xylooligosaccharides on the improvement of microbiota balance in human subjects. Gastroenterol. Res. Pract. 2016, 5789232. http:// dx.doi.org/10.1155/2016/5789232.

Liu, B., and Newburg, D.S. (2013). Human milk glycoproteins protect infants against human pathogens. Breastfeed. Med. 8, 354-362. http:// dx.doi.org/10.1089/bfm.2013.0016.

Liu, J.R., Yu, B., Liu, F.H., Cheng, K.J., and Zhao, X. (2005). Expression of rumen microbial fibrolytic enzyme genes in probiotic Lactobacillus reuteri. Appl. Environ. Microbiol. 71, 6769-6775. http:// dx.doi.org/10.1128/AEM.71.11.6769-6775.2005.

LoCascio, R.G., Desai, P., Sela, D.A., Weimer, B., and Mills, D.A. (2010). Broad conservation of milk utilization genes in Bifidobacterium longum subsp. infantis as revealed by comparative genomic hybridization. Appl. Environ. Microbiol. 76, 7373-7381. http://dx.doi.org/10.1128/AEM. 00675-10.

Lokman, B.C., van Santen, P., Verdoes, J.C., Krüse, J., Leer, R.J., Posno, M., and Pouwels, P.H. (1991). Organization and characterization of three genes involved in D-xylose catabolism in Lactobacillus pentosus. Molecular and General Genetics 230, 161-169.

Lozupone, C.A., Stombaugh, J.I., Gordon, J.I., Jansson, J.K., and Knight, R. (2012). Diversity, stability and resilience of the human gut microbiota. Nature 489, 220-230. http://dx.doi.org/ 10.1038/nature11550.

Macfarlane, G.T., Steed, H., and Macfarlane, S. (2008). Bacterial metabolism and health-related effects of galacto-oligosaccharides and other prebiotics. J. Appl. Microbiol. 104, 305-344. http:// dx.doi.org/10.1111/j.1365-2672.2007.03520.x.

Makras, L., Van Acker, G., and De Vuyst, L. (2005). Lactobacillus paracasei subsp. paracasei 8700:2 degrades inulin-type fructans exhibiting different degrees of polymerization. Appl. Environ. Microbiol. 71, 6531-6537. http://dx.doi.org/ 10.1128/aem.71.11.6531-6537.2005.

Malang, S.K., Maina, N.H., Schwab, C., Tenkanen, M., and Lacroix, C. (2015). Characterization of exopolysaccharide and ropy capsular polysaccharide formation by Weissella. Food Microbiol. 46, 418-427. http://dx.doi.org/10.1016/ j.fm.2014.08.022.

Marionneau, S., Cailleau-Thomas, A., Rocher, J., Le Moullac-Vaidye, B., Ruvoën, N., Clément, M., and Le Pendu, J. (2001). ABH and Lewis histo-blood group antigens, a model for the meaning of oligosaccharide diversity in the face of a changing world. Biochimie 83, 565-573. https://doi.org/ 10.1016/S0300-9084(01)01321-9.

Martin-Verstraete, I., Charrier, V., Stülke, J., Galinier, A., Erni, B., Rapoport, G., and Deutscher, J. (1998). Antagonistic effects of dual PTS-catalysed phosphorylation on the Bacillus subtilis transcriptional activator LevR. Mol. Microbiol. 28, 293-303. http://dx.doi.org/10.1046/j. 1365-2958.1998.00781.x.

Martín, R., Heilig, G.H., Zoetendal, E.G., Smidt, H., and Rodríguez, J.M. (2007). Diversity of the Lactobacillus group in breast milk and vagina of healthy women and potential role in the colonization of the infant gut. J. Appl. Microbiol. 103, 2638-2644. http://dx.doi.org/10.1111/j. 1365-2672.2007.03497.x.

Mazé, A., Boël, G., Poncet, S., Mijakovic, I., Le Breton, Y., Benachour, A., Monedero, V., Deutscher, J., and Hartke, A. (2004). The Lactobacillus casei ptsHI47T mutation causes overexpression of a LevR-regulated but RpoNindependent operon encoding a mannose class phosphotransferase system. J. Bacteriol. 186, 4543-4555. http://dx.doi.org/10.1128/jb. 186.14.4543-4555.2004.

Membrez, M., Blancher, F., Jaquet, M., Bibiloni, R., Cani, P.D., Burcelin, R.G., Corthesy, I., Macé, K., and Chou, C.J. (2008). Gut microbiota modulation with norfloxacin and ampicillin enhances glucose tolerance in mice. FASEB J. 22, 2416-2426. http:// dx.doi.org/10.1096/fj.07-102723.

Merry, R.J., Winters, A.L., Thomas, P.I., Müller, M., and Müller, T. (1995). Degradation of fructans by epiphytic and inoculated lactic acid bacteria and by plant enzymes during ensilage of normal and sterile hybrid ryegrass. J. Appl. Bacteriol. 79, 583-591. http://dx.doi.org/10.1111/j. 1365-2672.1995.tb00941.x.

Michlmayr, H., Hell, J., Lorenz, C., Böhmdorfer, S., Rosenau, T., and Kneifel, W. (2013). Arabinoxylan 
oligosaccharide hydrolysis by family 43 and 51 glycosidases from Lactobacillus brevis DSM 20054. Appl. Environ. Microbiol. 79, 6747-6754. http://dx.doi.org/10.1128/AEM.02130-13.

Michlmayr, H., Schümann, C., Kulbe, K.D., and del Hierro, A.M. (2011). Heterologously expressed family 51 alpha-L-arabinofuranosidases from Oenococcus oeni and Lactobacillus brevis. Appl. Environ. Microbiol. 77, 1528-1531. http:// dx.doi.org/10.1128/AEM.01385-10.

Miller, E.A., Beasley, D.E., Dunn, R.R., and Archie, E.A. (2016). Lactobacilli dominance and vaginal $\mathrm{pH}$ : why is the human vaginal microbiome unique? Front. Microbiol. 7, 1936. http:// dx.doi.org/10.3389/fmicb.2016.01936.

Møller, M.S., Fredslund, F., Majumder, A., Nakai, H., Poulsen, J.C., Lo Leggio, L., Svensson, B., and Abou Hachem, M. (2012). Enzymology and structure of the GH13_31 glucan 1,6-alphaglucosidase that confers isomaltooligosaccharide utilization in the probiotic Lactobacillus acidophilus NCFM. J. Bacteriol. 194, 4249-4259. http://dx.doi.org/10.1128/JB.00622-12.

Møller, M.S., Goh, Y.J., Rasmussen, K.B., Cypryk, W., Celebioglu, H.U., Klaenhammer, T.R., Svensson, B., and Abou Hachem, M. (2017). An extracellular cell-attached pullulanase confers branched alpha-glucan utilization in human gut Lactobacillus acidophilus. Appl. Environ. Microbiol. 83. http://dx.doi.org/10.1128/AEM. 00402-17.

Monedero, V., Yebra, M.J., Poncet, S., and Deutscher, J. (2008). Maltose transport in Lactobacillus casei and its regulation by inducer exclusion. Res. Microbiol. 159, 94-102. http:// dx.doi.org/10.1016/j.resmic.2007.10.002.

Moraïs, S., Shterzer, N., Lamed, R., Bayer, E.A., and Mizrahi, I. (2014). A combined cell-consortium approach for lignocellulose degradation by specialized Lactobacillus plantarum cells. Biotechnol. Biofuels 7, 112. http://dx.doi.org/ 10.1186/1754-6834-7-112.

Moran, A.P., Gupta, A., and Joshi, L. (2011). Sweettalk: role of host glycosylation in bacterial pathogenesis of the gastrointestinal tract. Gut 60 , 1412-1425. http://dx.doi.org/10.1136/gut. 2010.212704 .

Morlon-Guyot, J., Mucciolo-Roux, F., Rodriguez Sanoja, R., and Guyot, J.P. (2001). Characterization of the L. manihotivorans alphaamylase gene. DNA Seq. 12, 27-37. https:// doi.org/10.3109/10425170109042048.

Müller, M., and Lier, D. (1994). Fermentation of fructans by epiphytic lactic acid bacteria. J. Appl.
Bacteriol. 76, 406-411. http://dx.doi.org/10.1111/j. 1365-2672.1994.tb01647.x.

Müller, M., and Seyfarth, W. (1997). Purification and substrate specificity of an extracellular fructanhydrolase from Lactobacillus paracasei ssp. paracasei P 4134. New Phytol. 136, 89-96. h t t p : / / d x.doi.org/10.1046/j . 1469-8137.1997.00725.x.

Müller, M., and Steller, J. (1995). Comparative studies of the degradation of grass fructan and inulin by strains of Lactobacillus paracasei subsp. paracasei and Lactobacillus plantarum. J. Appl. Bacteriol. 78, 229-236. http://dx.doi.org/10.1111/j. 1365-2672.1995.tb05021.x.

Muscariello, L., Vastano, V., Siciliano, R.A., Sacco, M., and Marasco, R. (2011). Expression of the Lactobacillus plantarum malE gene is regulated by CcpA and a MalR-like protein. J. Microbiol. 49, 950-955. http://dx.doi.org/10.1007/ s12275-011-0495-5.

Mysore, J.V., Wigginton, T., Simon, P.M., Zopf, D., Heman-Ackah, L.M., and Dubois, A. (1999). Treatment of Helicobacter pylori infection in rhesus monkeys using a novel antiadhesion compound. Gastroenterology 117, 1316-1325. http://dx.doi.org/10.1016/S0016-5085(99)70282-9.

Nácher-Vázquez, M., Iturria, I., Zarour, K., Mohedano, M.L., Aznar, R., Pardo, M.A., and López, P. (2017). Dextran production by Lactobacillus sakei MN1 coincides with reduced autoagglutination, biofilm formation and epithelial cell adhesion. Carbohydr. Polymers 168, 22-31. http://dx.doi.org/10.1016/j.carbpol.2017.03.024.

Nakai, H., Baumann, M.J., Petersen, B.O., Westphal, Y., Schols, H., Dilokpimol, A., Hachem, M.A., Lahtinen, S.J., Duus, J.O., and Svensson, B. (2009). The maltodextrin transport system and metabolism in Lactobacillus acidophilus NCFM and production of novel alpha-glucosides through reverse phosphorolysis by maltose phosphorylase. FEBS J. 276, 7353-7365. http:// dx.doi.org/10.1111/j.1742-4658.2009.07445.x.

Nakamura, L.K. (1981). Lactobacillus amylovorus, a new starch-hydrolyzing species from cattle wastecorn fermentations. Int. J. Syst. Evol. Microbiol. 31, $56-63$. http://dx.doi.org/doi: 10.1099/00207713-31-1-56.

Nakamura, L.K., and Crowell, C.D. (1979). Lactobacillus amylophilus, a new starchhydrolyzing species from swine waste-corn fermentation. . Dev. Ind. Microbiol. 20, 532-540.

Neubauer, H., Glaasker, E., Hammes, W.P., Poolman, B., and Konings, W.N. (1994). Mechanism of maltose uptake and glucose excretion in Lactobacillus sanfrancisco. J. 
Bacteriol. 176, 3007-3012. http://dx.doi.org/ 10.1128/jb.176.10.3007-3012.1994.

Newburg, D.S., Ruiz-Palacios, G.M., and Morrow, A.L. (2005). Human milk glycans protect infants against enteric pathogens. Annu. Rev. Nutr. 25, 37-58. http://dx.doi.org/10.1146/annurev.nutr. 25.050304.092553.

Nwosu, C.C., Aldredge, D.L., Lee, H., Lerno, L.A., Zivkovic, A.M., German, J.B., and Lebrilla, C.B. (2012). Comparison of the human and bovine milk $\mathrm{N}$-glycome via high-performance microfluidic chip liquid chromatography and tandem mass spectrometry. J. Proteome Res. 11, 2912-2924. http://dx.doi.org/10.1021/pr300008u.

O' Donnell, M.M., Forde, B.M., Neville, B., Ross, P.R., and O' Toole, P.W. (2011). Carbohydrate catabolic flexibility in the mammalian intestinal commensal Lactobacillus ruminis revealed by fermentation studies aligned to genome annotations. Microb. Cell Fact. 10, S12-S12. http://dx.doi.org/10.1186/1475-2859-10-S1-S12.

Okano, K., Zhang, Q., Yoshida, S., Tanaka, T., Ogino, C., Fukuda, H., and Kondo, A. (2010). Dlactic acid production from cellooligosaccharides and beta-glucan using L-LDH gene-deficient and endoglucanase-secreting Lactobacillus plantarum. Appl. Microbiol. Biotechnol. 85, 643-650. http:// dx.doi.org/10.1007/s00253-009-2111-8.

Olivares-Illana, V., López-Munguía, A., and Olvera, C. (2003). Molecular characterization of inulosucrase from Leuconostoc citreum: a fructosyltransferase within a glucosyltransferase. J. Bacteriol. 185, 3606-3612. http://dx.doi.org/ 10.1128/JB.185.12.3606-3612.2003.

Öner, E.T., Hernández, L., and Combie, J. (2016). Review of levan polysaccharide: from a century of past experiences to future prospects. Biotech. Adv. 34, 827-844. http://dx.doi.org/10.1016/ j.biotechadv.2016.05.002.

Overbeck, T., Steele, J.L., and Broadbent, J.R. (2016). Fermentation of de-oiled algal biomass by Lactobacillus casei for production of lactic acid. Bioprocess Biosyst. Eng. 39, 1817-1823. http:// dx.doi.org/10.1007/s00449-016-1656-z.

Paludan-Müller, C., Gram, L., and Rattray, F.P. (2002). Purification and characterisation of an extracellular fructan $\beta$-fructosidase from a Lactobacillus pentosus strain isolated from fermented fish. Syst. Appl. Microbiol. 25, 13-20. http://dx.doi.org/10.1078/0723-2020-00101.

Petrova, P., and Petrov, K. (2012). Direct starch conversion into $\mathrm{L}-(+)$-lactic acid by a novel amylolytic strain of Lactobacillus paracasei B41. Starch 64, 10-17. http://dx.doi.org/10.1002/star. 201100074.
Petrova, P., Petrov, K., and Stoyancheva, G. (2013). Starch-modifying enzymes of lactic acid bacteria structures, properties and applications. Starch 65, 34-47. http://dx.doi.org/10.1002/star.201200192.

Pfeiler, E.A., Azcarate-Peril, M.A., and Klaenhammer, T.R. (2007). Characterization of a novel bile-inducible operon encoding a twocomponent regulatory system in Lactobacillus acidophilus. J. Bacteriol. 189, 4624-4634. http:// dx.doi.org/10.1128/JB.00337-07.

Puyet, A., Ibáñez, A.M., and Espinosa, M. (1993). Characterization of the Streptococcus pneumoniae maltosaccharide regulator MalR, a member of the Lacl-GalR family of repressors displaying distinctive genetic features. J. Biol. Chem. 268, 25402-25408.

Rastall, R.A., Gibson, G.R., Gill, H.S., Guarner, F., Klaenhammer, T.R., Pot, B., Reid, G., Rowland, I.R., and Sanders, M.E. (2005). Modulation of the microbial ecology of the human colon by probiotics, prebiotics and synbiotics to enhance human health: an overview of enabling science and potential applications. FEMS Microbiol. Ecol. 52, 145-152. http://dx.doi.org/10.1016/j.femsec. 2005.01.003.

Roberfroid, M.B., Van Loo, J.A.E., and Gibson, G.R. (1998). The bifidogenic nature of chicory inulin and its hydrolysis products. J. Nutr. 128, 11-19.

Rodriguez-Colinas, B., de Abreu, M.A., FernandezArrojo, L., de Beer, R., Poveda, A., JimenezBarbero, J., Haltrich, D., Ballesteros Olmo, A.O., Fernandez-Lobato, M., and Plou, F.J. (2011). Production of galacto-oligosaccharides by the beta-galactosidase from Kluyveromyces lactis : comparative analysis of permeabilized cells versus soluble enzyme. J. Agric. Food Chem. 59, 10477-10484. http://dx.doi.org/10.1021/jf2022012.

Rodríguez-Díaz, J., Carbajo, R.J., Pineda-Lucena, A., Monedero, V., and Yebra, M.J. (2013). Synthesis of fucosyl-N-acetylglucosamine disaccharides by transfucosylation using alpha-Lfucosidases from Lactobacillus casei. Appl. Environ. Microbiol. 79, 3847-3850. http:// dx.doi.org/10.1128/AEM.00229-13.

Rodríguez-Díaz, J., Monedero, V., and Yebra, M.J. (2011). Utilization of natural fucosylated oligosaccharides by three novel alpha-Lfucosidases from a probiotic Lactobacillus casei strain. Appl. Environ. Microbiol. 77, 703-705. http://dx.doi.org/10.1128/AEM.01906-10.

Rodríguez-Díaz, J., Rubio-del-Campo, A., and Yebra, M.J. (2012). Lactobacillus casei ferments the N-Acetylglucosamine moiety of fucosylalpha-1,3-N-acetylglucosamine and excretes L- 
fucose. Appl. Environ. Microbiol. 78, 4613-4619. http://dx.doi.org/10.1128/AEM.00474-12.

Rodriguez Sanoja, R., Morlon-Guyot, J., Jore, J., Pintado, J., Juge, N., and Guyot, J.P. (2000). Comparative characterization of complete and truncated forms of Lactobacillus amylovorus alpha-amylase and role of the C-terminal direct repeats in raw-starch binding. Appl. Environ. Microbiol. 66, 3350-3356. http://dx.doi.org/ 10.1128/AEM.66.8.3350-3356.2000.

Rubio, R., Jofré, A., Martín, B., Aymerich, T., and Garriga, M. (2014). Characterization of lactic acid bacteria isolated from infant faeces as potential probiotic starter cultures for fermented sausages. Food Microbiol. 38, 303-311. http://dx.doi.org/ 10.1016/j.fm.2013.07.015.

Ruiz-Palacios, G.M., Cervantes, L.E., Ramos, P., Chavez-Munguia, B., and Newburg, D.S. (2003). Campylobacter jejuni binds intestinal $\mathrm{H}(\mathrm{O})$ antigen (Fuc-alpha-1, 2Gal-beta-1, 4GIcNAc), and fucosyloligosaccharides of human milk inhibit its binding and infection. J. Biol. Chem. 278, 14112-14120. http://dx.doi.org/10.1074/ jbc.M207744200.

Sangwan, V., Tomar, S.K., Singh, R.R., Singh, A.K., and Ali, B. (2011). Galactooligosaccharides: novel components of designer foods. Journal of Food Science 76, R103-111. http://dx.doi.org/10.1111/j. 1750-3841.2011.02131.x.

Saulnier, D.M.A., Molenaar, D., de Vos, W.M., Gibson, G.R., and Kolida, S. (2007). Identification of prebiotic fructooligosaccharide metabolism in Lactobacillus plantarum WCFS1 through microarrays. Appl. Environ. Microbiol. 73, 1753-1765. http://dx.doi.org/10.1128/aem. 01151-06.

Schnaar, R.L., Suzuki, A., and Stanley, P. (2009). Glycosphingolipids. In Essentials of Glycobiology, A. Varki, R.D. Cummings, J.D. Esko, H.H. Freeze, P. Stanley, C.R. Bertozzi, G.W. Hart, and M.E. Etzler, eds. (Cold Spring Harbor (NY)). http:// dx.doi.org/10.1101/glycobiology.3e.011.

Sghir, A., Chow, J.M., and Mackie, R.I. (1998). Continuous culture selection of bifidobacteria and lactobacilli from human faecal samples using fructooligosaccharide as selective substrate. J. Appl. Microbiol. 85, 769-777. http://dx.doi.org/ 10.1111/j.1365-2672.1998.00590.x.

Silvestroni, A., Connes, C., Sesma, F., De Giori, G.S., and Piard, J.C. (2002). Characterization of the melA locus for alpha-galactosidase in Lactobacillus plantarum. Appl. Environ. Microbiol. 68, 5464-5471. http://dx.doi.org/10.1128/AEM. 68.11.5464-5471.2002.
Sommer, F., Anderson, J.M., Bharti, R., Raes, J., and Rosenstiel, P. (2017). The resilience of the intestinal microbiota influences health and disease. Nat. Rev. Microbiol. 15, 630-638. http:// dx.doi.org/10.1038/nrmicro.2017.58.

Sonnenburg, J.L., and Backhed, F. (2016). Dietmicrobiota interactions as moderators of human metabolism. Nature 535, 56-64. http://dx.doi.org/ 10.1038/nature18846.

Stearns, J.C., Lynch, M.D.J., Senadheera, D.B., Tenenbaum, H.C., Goldberg, M.B., Cvitkovitch, D.G., Croitoru, K., Moreno-Hagelsieb, G., and Neufeld, J.D. (2011). Bacterial biogeography of the human digestive tract. Sci. Rep. 1, 170. http:// dx.doi.org/10.1038/srep00170.

Stefanovic, E., Fitzgerald, G., and McAuliffe, O. (2017). Advances in the genomics and metabolomics of dairy lactobacilli: a review. Food Microbiol. 61, 33-49. http://dx.doi.org/10.1016/ j.fm.2016.08.009.

Tannock, G.W. (2004). A special fondness for lactobacilli. Appl. Environ. Microbiol. 70, 3189-3194. http://dx.doi.org/10.1128/aem. 70.6.3189-3194.2004.

Thongaram, T., Hoeflinger, J.L., Chow, J., and Miller, M.J. (2017). Prebiotic galactooligosaccharide metabolism by probiotic lactobacilli and bifidobacteria. J. Agric. Food Chem. 65, 4184-4192. http://dx.doi.org/10.1021/acs.jafc. $7 \mathrm{~b} 00851$.

Thurl, S., Munzert, M., Henker, J., Boehm, G., Muller-Werner, B., Jelinek, J., and Stahl, B. (2010). Variation of human milk oligosaccharides in relation to milk groups and lactational periods. Br. J. Nutr. 104, 1261-1271. http://dx.doi.org/ 10.1017/S0007114510002072.

Tieking, M., Korakli, M., Ehrmann, M.A., Gänzle, M.G., and Vogel, R.F. (2003). In situ production of exopolysaccharides during sourdough fermentation by cereal and intestinal isolates of lactic acid bacteria. Appl. Environ. Microbiol. 69, 945-952. http://dx.doi.org/10.1128/aem. 69.2.945-952.2003.

Tropini, C., Earle, K.A., Huang, K.C., and Sonnenburg, J.L. (2017). The gut microbiome: connecting spatial organization to function. Cell Host Microbe 21, 433-442. http://dx.doi.org/ 10.1016/j.chom.2017.03.010.

Turnbaugh, P.J., Hamady, M., Yatsunenko, T., Cantarel, B.L., Duncan, A., Ley, R.E., Sogin, M.L., Jones, W.J., Roe, B.A., Affourtit, J.P., et al. (2009). A core gut microbiome in obese and lean twins. Nature 457, 480-484. http://dx.doi.org/10.1038/ nature 07540 . 
Tzortzis, G., Jay, A.J., Baillon, M.L., Gibson, G.R., and Rastall, R.A. (2003). Synthesis of alphagalactooligosaccharides with alpha-galactosidase from Lactobacillus reuteri of canine origin. Appl. Microbiol. Biotechnol. 63, 286-292. http:// dx.doi.org/10.1007/s00253-003-1426-0.

Urashima, T., Taufik, E., Fukuda, K., and Asakuma, S. (2013). Recent advances in studies on milk oligosaccharides of cows and other domestic farm animals. Biosci. Biotechnol. Biochem. 77, 455-466. http://dx.doi.org/10.1271/bbb.120810.

Vaarala, O., Atkinson, M.A., and Neu, J. (2008). The "perfect storm" for type 1 diabetes: the complex interplay between intestinal microbiota, gut permeability, and mucosal immunity. Diabetes 57 , 2555-2562. http://dx.doi.org/10.2337/db08-0331.

van Arkel, J., Sévenier, R., Hakkert, J.C., Bouwmeester, H.J., Koops, A.J., and van der Meer, I.M. (2013). Tailor-made fructan synthesis in plants: a review. Carbohydr. Polymers 93, 48-56. http://dx.doi.org/10.1016/j.carbpol.2012.02.001.

Van Geel-Schutten, G.H., Faber, E.J., Smit, E., Bonting, K., Smith, M.R., Ten Brink, B., Kamerling, J.P., Vliegenthart, J.F.G., and Dijkhuizen, L. (1999). Biochemical and structural characterization of the glucan and fructan exopolysaccharides synthesized by the Lactobacillus reuteri wild-type strain and by mutant strains. Appl. Environ. Microbiol. 65, 3008-3014.

van Hijum, S.A.F.T., van Geel-Schutten, G.H., Rahaoui, H., van der Maarel, M.J.E.C., and Dijkhuizen, L. (2002). Characterization of a novel fructosyltransferase from Lactobacillus reuteri that synthesizes high-molecular-weight inulin and inulin oligosaccharides. Appl. Environ. Microbiol. 68, 4390-4398. http://dx.doi.org/10.1128/aem. 68.9.4390-4398.2002.

Velikova, P., Petrov, K., and Petrova, P. (2017). The cell wall anchored $\beta$-fructosidases of Lactobacillus paracasei: overproduction, purification, and gene expression control. Process Biochem. 52, 53-62. https://doi.org/10.1016/j.procbio.2016.10.010.

Vera, C., Córdova, A., Aburto, C., Guerrero, C., Suárez, S., and Illanes, A. (2016). Synthesis and purification of galacto-oligosaccharides: state of the art. World J. Microbiol. Biotechnol. 32, 197. http://dx.doi.org/10.1007/s11274-016-2159-4.
Wang, L., Yang, Y., Cai, B., Cao, P., Yang, M., and Chen, Y. (2014a). Coexpression and secretion of endoglucanase and phytase genes in Lactobacillus reuteri. Int. J. Mol. Sci. 15, 12842-12860. http://dx.doi.org/10.3390/ ijms150712842.

Wang, Y., Black, B.A., Curtis, J.M., and Ganzle, M.G. (2014b). Characterization of alpha-galactooligosaccharides formed via heterologous expression of alpha-galactosidases from Lactobacillus reuteri in Lactococcus lactis. Appl. Microbiol. Biotechnol. 98, 2507-2517. http:// dx.doi.org/10.1007/s00253-013-5145-x.

Weckx, S., Allemeersch, J., Van der Meulen, R., Vrancken, G., Huys, G., Vandamme, P., Van Hummelen, P., and De Vuyst, L. (2011). Metatranscriptome analysis for insight into wholeecosystem gene expression during spontaneous wheat and spelt sourdough fermentations. Appl. Environ. Microbiol. 77, 618-626. http://dx.doi.org/ 10.1128/AEM.02028-10.

Winters, Merry, Müller, Davies, Pahlow, and Müller (1998). Degradation of fructans by epiphytic and inoculant lactic acid bacteria during ensilage of grass. J. Appl. Microbiol. 84, 304-312. http:// dx.doi.org/10.1046/j.1365-2672.1998.00342.x.

Yazawa, K., and Tamura, Z. (1982). Search for sugar sources for selective increase of bifidobacteria. Bifidobact. Microfl. 1, 39-44.

Yen, C.H., Tseng, Y.H., Kuo, Y.W., Lee, M.C., and Chen, H.L. (2011). Long-term supplementation of isomalto-oligosaccharides improved colonic microflora profile, bowel function, and blood cholesterol levels in constipated elderly people--a placebo-controlled, diet-controlled trial. Nutrition 27, 445-450. http://dx.doi.org/10.1016/j.nut. 2010.05.012.

Yu, Z.T., Chen, C., and Newburg, D.S. (2013). Utilization of major fucosylated and sialylated human milk oligosaccharides by isolated human gut microbes. Glycobiology 23, 1281-1292. http:// dx.doi.org/10.1093/glycob/cwt065.

Zúñiga, M., Monedero, V., and Yebra, M.J. (2018). Utilization of host-derived glycans by intestinal Lactobacillus and Bifidobacterium species. Front. Microbiol. 9, 1917. https://doi.org/10.3389/fmicb. 2018.01917. 